\title{
Marine Fungal Metabolite Butyrolactone I Prevents Cognitive Deficits and Inflammation Evoked by AlCl3 in zebrafish
}

\section{Yingying Nie}

Guangdong Ocean University https://orcid.org/0000-0002-1092-8297

Jingming Yang

Guangdong Ocean University

Jinyue Liang

Guangdong Ocean University

Zhiyou Yang

Guangdong Ocean University

\section{Longjian Zhou}

Tianjin University

\section{Yayue Liu}

Guangdong Ocean University

Xiaoxiang Ma

Guangdong Ocean University

Zhongji Qian

Guangdong Ocean University

\section{Pengzhi Hong}

Guangdong Ocean University

Allan V Kalueff

Ural Federal University

\section{Cai Song}

Guangdong Ocean University

Yi Zhang ( $\nabla$ hubeizhangyi@163.com )

Shenzhen Institute of Guangdong Ocean University https://orcid.org/0000-0002-1600-7456

\section{Research}

Keywords: Inflammation, Oxidative stress, Butyrolactone I, Neurodegenerative diseases, Acetylcholinesterase, Intestinal flora

Posted Date: July 15th, 2021 
DOI: https://doi.org/10.21203/rs.3.rs-685780/v1

License: (c) (1) This work is licensed under a Creative Commons Attribution 4.0 International License. Read Full License 


\section{Abstract}

\section{Background}

Mounting evidences indicate that oxidative stress and neuroinflammation are related to neurodegenerative disorders (NDs). Butyrolactone I (BTL-I), a marine fungal metabolite, was previously reported as an in-vitro neuroprotectant and inflammation inhibitor. However, little is known about its invivo effects. Zebrafish (Danio rerio) could be used as a convenient model in evaluation of toxicology and central nervous system (CNS) diseases.

\section{Methods}

Here, we employ the in-vivo and in-silico methods to investigate the anti-NDs potential of BTL-I. Specifically, we established cognitive deficits model in zebrafish by intraperitoneal (i.p.) injection of $\mathrm{AlCl}_{3}$ $(21 \mu \mathrm{g})$, and assessed their behaviors in the T-maze test. Proinflammatory cytokines interleukin-1 $\beta$ (IL-1 $\beta$ ) and tumor necrosis factor-a (TNF-a), as well as acetylcholinesterase (AChE) activity, glutathione (GSH) levels were assayed $24 \mathrm{~h}$ after the $\mathrm{AlCl}_{3}$ injection. The intestinal flora of the zebrafish were investigated by $16 \mathrm{~S} \mathrm{rDNA}$ high-throughput analysis. A marine fungal metabolite, butyrolactone I (BTL-I) was used to modulate zebrafish cognitive deficits evoked by $\mathrm{AlCl}_{3}$. The absorption, distribution, metabolism, excretion, and toxicity (ADMET) and drug-likeness properties of BTL-I were studied by in-silico tool of ADMETlab.

\section{Results}

BTL-I dose-dependently ameliorated $\mathrm{AlCl}_{3}$-induced cognitive deficits in zebrafish. While, $\mathrm{AlCl}_{3}$ treatment elevated the levels of central and peripheral proinflammatory cytokines, increased AChE activity, and lowered GSH in the brain of zebrafish, these effects except GSH reducing were reversed by $25-100$ $\mathrm{mg} / \mathrm{kg} \mathrm{BTL}-\mathrm{I}$ administration. 16S rDNA high-throughput sequencing of intestinal flora of zebrafish showed that $\mathrm{AlCl}_{3}$ decreased Gram-positive bacteria and increased proinflammatory Gram-negative bacterial while BTL-I contributed to maintain the predominance of beneficial Gram-positive bacteria. The in-silico analysis indicated that BTL-I exhibits acceptable drug-likeness and ADMET profiles.

\section{Conclusions}

The present findings suggest BTL-I as a potential therapeutic agent for preventing CNS deficits caused by inflammation, neurotoxicity, and gut flora imbalance.

\section{Background}

Neurodegenerative disorders (NDs), such as Alzheimer's disease (AD) and Parkinson's disease (PD), are chronic, progressive and severely debilitating neurological disorders [1, 2]. NDs are characterized by cognitive and motor deficits, accompanied by neuronal apoptosis and reduced neurotransmission $[3,4]$. Oxidative stress and inflammation play key roles in neuronal apoptosis [5-9], and may thus be 
considered as potential risk factors for NDs. Various factors, including peripheral or brain inflammation, $\beta$-amyloid peptide $(A \beta)$, pathogenic infection and toxins (e.g., aluminum) activate brain microglial cells [10-12]. The release of proinflammatory cytokines and reactive oxygen species (ROS) trigger and amplify damage of neurons and astrocytes, whereas oxidative stress and inflammation further promoting neuroinflammation, which, in turn, activates microglia, eventually impairing neurons and astrocytes $[5,7$, 12-14]. Oxidative stress and inflammation are involved in cyclin-dependent kinase 5 (CDK 5) activationinduced Tau hyperphosphorylation, resulting in neurofibrillary tangles, another important pathological marker of $A D$ [5]. In addition, increasing studies have shown that intestinal microorganisms were closely related to the occurrence of NDs $[15,16]$.

Notably, current clinical drugs for the prevention and treatment of NDs just manifest limited efficacy. For example, donepezil partially relieve symptoms of AD without reversing or preventing its progression [5]. The poor understanding of NDs pathogenesis restricted new drug development $[17,18]$. The repeated failure to develop anti-AD drugs targeting orphan targets, such as $A \beta$ and Tau, may be substantially related to malignant amplification induced by neuroinflammation and oxidative stress. Thus, inhibiting inflammation and oxidative stress to protect neurons and intervene in the early stage of disease has become important new strategy in developing novel anti-ND agents [19]. Aryl butyrolactones (BTLs), including butyrolactone I (BTL-I, Fig. 1 inset), are characteristic natural products of fungi (e.g., Aspergillus sp. and Penicillium sp.) $[20,21]$. Our previous studies have shown that BTL-I has strong in vitro antineuroinflammatory effects, inhibiting LPS-induced inflammatory proliferation of microglia, the release of inflammatory mediators (NO and IL-1 3 ) and ROS, as well as the expression of inflammatory target enzyme cyclooxygenase-2 (COX-2), and intracellular migration of the signaling protein NF-kB p65 [22]. Moreover, BTL-I plays a versatile anti-neurodegenerative role through multiple mechanisms, such as neuronal nutrition and inhibiting neuronal injury [23-26]. However, since previous BTL-I studies were limited to in vitro, its in vivo effects remain to be elucidated.

Due to their high genetic and physiological homology to humans, the zebrafish has long been used as an powerful in vivo model to assess anti-inflammatory drugs [27, 28] and neuronal injury [29]. Zebrafish possess innate and acquired immune systems similar to those of mammals [30], and display wellcharacterized learning, memory, addiction and other behaviors that corresponding to clinical phenotypes [31-34].

$\mathrm{AlCl}_{3}$ causes AD-like pathology, aggravating neuroinflammation, oxidative stress and AChE activity in the rodent's brain [12,35,36]. The effect of $\mathrm{AlCl}_{3}$ on zebrafish cognition remains unclear [37]. In the present study, we established a neurotoxic zebrafish model (induced by $\mathrm{AlCl}_{3}$ ) to assess potential effects of BTL-I on memory and cognitive impairment in vivo. The putative neuroprotective activity of BTL-I in zebrafish was further investigated by evaluating AChE activity and GSH levels in the brain, and by detecting the levels of the inflammatory cytokines IL-1 $\beta$ and TNF- $a$ in both central and peripheral tissues. 16S rDNA high-throughput method was used to determine the structure and changes of zebrafish intestinal flora. The in-silico tool of ADMETlab was applied to evaluate the absorption, distribution, metabolism, excretion, and toxicity (ADMET) and drug-likeness properties of BTL-I. 


\section{Methods}

\section{Animals and model development}

Adult wild-type $A B$ zebrafish (approximately 6-8 months old; 50:50\% male: female ratio) used in the present study were obtained from a commercial supplier (Shanghai Jiayu Aquarium, Shanghai, China) and acclimatized in a $50 \mathrm{~L}$ aquarium in the aquatic facility of the Guangdong Ocean University for at least 2 weeks. The fish were kept on a $14 \mathrm{~h}: 10 \mathrm{~h}$ light: dark cycle (lights on at $7 \mathrm{am}$ ) at a temperature of $25 \pm 2{ }^{\circ} \mathrm{C}$ in a recirculating tank system. The zebrafish were maintained according to standard conditions [38], and fed Artemis larvae twice a day, at 9 am and 2 pm.

As shown in Fig. 1, to establish an $\mathrm{AlCl}_{3}$ model, 75 zebrafish $(3.0 \pm 0.4 \mathrm{~cm}$ in length) were randomly divided into control, $\mathrm{AlCl}_{3}$ and BTL-I treated groups ( $n=15$ per group). BTL-I ( 25,50 or $\left.100 \mathrm{mg} / \mathrm{kg} / \mathrm{day}\right)$ was administered with food for 20 days. The control and $\mathrm{AlCl}_{3}$ groups were fed equal amounts of normal food. 20 days later, the $\mathrm{AlCl}_{3}$ and $\mathrm{BTL}-\mathrm{I}$ groups were anesthetized and injected (i.p.) with $\mathrm{AlCl}_{3}$ solution $(4.2 \mathrm{mg} / \mathrm{mL}, 5 \mu \mathrm{L}, \mathrm{pH}=5.0 \pm 0.2)$ using a $10-\mu \mathrm{L}$ gas phase injection needle $0.5 \mathrm{~mm}$ in the outer diameter. The control group was injected with the same amount of saline. Memory testing was performed $24 \mathrm{~h}$ later.

Briefly, following a 24-h fasting, the fish were anesthetized and then received an i.p. injection. For this, eugenol was dissolved in $100 \mathrm{~mL}$ anhydrous ethanol to prepare a $1 \mathrm{mg} / \mathrm{mL}$ stock solution that was added to $5 \mathrm{~L}$ of water $\left(28 \pm 1{ }^{\circ} \mathrm{C}\right)$ and stirred evenly. Zebrafish were then group-exposed to the anesthetic, and after stopping swimming (immobile $>2-3 \mathrm{~min}$ ), quickly injected with $\mathrm{AlCl}_{3}$. After the injection, the animals recovered in a water-containing beaker and returned to the holding tanks once their normal swimming resumed [39].

\section{T-maze behavioral testing}

The aquatic T- maze was used for cognitive testing, as described previously, with modifications [40, 41]. The maze comprised a long vertical arm $(50 \mathrm{~cm})$ and two short horizontal arms $(20 \mathrm{~cm})$, with an arm width of $10 \mathrm{~cm}$, a depth of $10 \mathrm{~cm}$, and the water depth of $8 \mathrm{~cm}$. The right arm was connected to a rectangular water tank $(22 \mathrm{~cm} \times 20 \mathrm{~cm} \times 15 \mathrm{~cm})$ with a black outer wall; sand and stones were added to the bottom of the tank, and bait was set inside the tank to provide an enriched chamber (EC) (Fig. 1). During the final 4 days of treatment, 6 fish were randomly selected from each group and the fish were individually trained for 5 min daily to locate the EC zone. If a fish did not enter the EC zone within the 5min training session, it was guided into the EC zone and kept there for $>30 \mathrm{~s}$. Following 4 days of training, one day later the trained fish were placed individually into the starting area of the long arm for behavioral testing, scoring the latency time (s) to enter the EC zone and stay there for $>30 \mathrm{~s}$. If a fish did not enter the EC zone within the 5-min test, the latency time was recorded as $300 \mathrm{~s}$. Behavioral testing was performed between 10 am and 1 pm. A Microsoft LifeCam Studio 1080p HD camera was used to record videos with Apowersoft software (Apowersoft Co. Ltd., Hong Kong, China). The Supersys software was used for off-line video analyses (Shanghai Xinruan Information Technology Co. Ltd., Shanghai, 
China), assessing the latency of the first entry into the EC zone (s), the average swimming speed (cm/s), and the number of EC entries.

\section{Reagents}

BTL-I was isolated for this study from the marine fungus Aspergillus terreus C23-3 as described previously [22]. The BCA protein-, GSH- and AChE assay kits, fish IL-1 $\beta$ enzyme-linked immunosorbent assay (ELISA) kit and fish TNF-a ELISA kit were purchased from Nanjing Jiancheng Bioengineering Institute (Nanjing, China). Eugenol and $\mathrm{AlCl}_{3}$ were purchased from Huaxia Reagent (Chengdu, China) and Xiya Reagent (Shandong, China), respectively.

\section{Molecular biomarker assays}

Twenty-four hours after behavioral testing, the fish were euthanized. Considering that the available assay kits could not measure the tiny tissue samples of individual fish, the 15 fish in each group were randomly divided into 3 subgroups, and samples of brain, peripheral tissue and intestinal tract from each subgroup (5 fish) were collected and combined immediately, and freeze-dried at $-80{ }^{\circ} \mathrm{C}$. All the samples (except for the gut samples) were homogenized in phosphate-buffered solution (PBS) for further assays. The supernatant was collected by centrifugation at $252 \mathrm{~g}$ at $4{ }^{\circ} \mathrm{C}$ for $15 \mathrm{~min}$. Zebrafish brain sample supernatants were used to determine GSH levels and AChE activity. Moreover, zebrafish brain sample and peripheral tissue supernatants were also used to determine the levels of IL-1 $\beta$ and TNF-a [42], following the manufacturer instructions. The results were expressed as $U$ of $A C h E / m g$ of protein and $\mu \mathrm{mol}$ of $\mathrm{GSH} / \mathrm{g}$ of protein. Regression equations for the IL-1 $\beta$ and TNF-a standard curves were calculated according to the OD value, and logistic curves (4 parameters each) were used as the fitting models.

\section{Statistical analysis for behavior and molecular biomarkers}

Statistical analysis was performed by one-way analysis of variance (ANOVA) followed by a post-hoc Dunnett test. The results are expressed as the mean \pm SD. P-value was set at $<0.05$ for all tests.

\section{Gut flora sequencing and data analysis}

Genomic DNA was extracted by protease K lysis. The variable region of $16 \mathrm{~S}$ ribosomal RNA gene V3-V4 was amplified by PCR, and the specific primer sequences were as follows: 357F 5'ACTCCTACGGRAGGCAGCAG-3' and 806R 5'-GGACTACHVGGGTWTCTAAT-3'. The bidirectional sequencing was performed according to Illumina high-throughput sequencing requirements, and the library was constructed by a two-step PCR amplification. The PCR conditions were $94{ }^{\circ} \mathrm{C}$ for 2 min; $94{ }^{\circ} \mathrm{C}$ for $30 \mathrm{~s}, 56^{\circ} \mathrm{C}$ for $30 \mathrm{~s}, 72^{\circ} \mathrm{C}$ for $30 \mathrm{~s}$ (the primary PCR amplification 30 cycles, the secondary PCR amplification 8 cycles), $72{ }^{\circ} \mathrm{C}$ for $5 \mathrm{~min}$, and a final extension at $10{ }^{\circ} \mathrm{C}$. PCR amplification products were recovered by $2 \%$ agarose gel electrophoresis. Recycling was performed using AxyPrepDNA gel recovery kit from Axygen.

The PCR amplified products of the zebrafish gut samples were sequenced for 16S rDNA using the Illumina-Misq high-throughput sequencing platform (TinyGene Bio-Tech (ShangHai) Co., Ltd, China) and 
the sequence length was $450 \mathrm{bp}$. The raw data obtained from sequencing were evaluated for quality and optimized. Trimmomatic was used for sequence filtration and FLASH was used for splicing. Ambiguous, homologous and some chimeras produced in PCR process were subsequently screened using Mothur V.1.39.5 to obtain optimized sequences for subsequent operational taxonomic unit (OTU) clustering and species information analysis.

USEARCH was used to cluster OTUs of the above treated sequences at $97 \%$ similarity. The representative OTU sequences were compared with the database Silva for species annotation (confidence threshold: 0.6). The relative abundance percentages of each sample were calculated at the levels of phylum, class, order, family, genus and species. Rarefaction curve reflects the sequencing depth of the samples. The rank-abundance curve explains species abundance and species evenness.

The Venn diagram can be used to count the common and unique OTU numbers of multiple samples, which can directly show the overlap and uniqueness in the OTU composition of different samples.

Alpha diversity analysis reflected the richness and diversity of communities in the samples. Mothur (http://www.mothur.org/wiki/Schloss_SOP\#Alpha_diversity) was used to calculate the values of Shannon, Simpson, chao and ace indices, and R(3.4.1) language tool was used for graph plotting.

Jaccard, Bray-curtis, unweighted-Unifrac, and weighted-Unifrac were used to calculate the differences between samples and conduct non-metric multidimensional scaling graphs (NMDS). Matastats (http://metastats.cbcb.umd.edu/) was used for the comparison of the features with different abundances between groups on multiple taxonomic levels. The non-parametric factorial Kruskal-Wallis (KW) sum-rank test was applied to determine the significant difference between the richness of the groups. LEfSe (LDA effect size) uses linear discriminant analysis (LDA) to estimate the impact of each component (species) abundance on the difference effect of the groups.

\section{In silico prediction of ADMET and drug-likeness properties of BTL-I}

To evaluate the pharmacokinetic profile and toxicity of BTL-I, we employed the ADMETlab 2.0 (https://admetmesh.scbdd.com/pub/), which is a free online platform that facilitates researcher to predict the ADMET and drug-likeness properties of a compound $[43,44]$.

\section{Results}

\section{BTL-I improved $\mathrm{AlCl}_{3}$-induced memory impairment}

Overall, compared with the model group, the BTL-I treated groups showed significant treatment effect for zebrafish cognitive performance in the T-maze test $(F(4,25)=40.60, P<0.001$ for the latency of first entry 
to the EC zone on day 5 in Fig. $2 a, F(4,25)=9.029, P<0.001$ for swimming speed in Fig. $2 b, F(4,25)=$ $31.65, P<0.001$ for the numbers of EC entries in Fig. $2 \mathrm{c}$ ).

Subsequent post-hoc testing revealed that zebrafish in the model group had an increased latency of first entry to the EC zone, reduced swimming speed and the number of EC entries (Figs. $2 b$ and $2 c$ ). The swimming tracks also clearly showed the reduced preference of the model group fish to the EC zone (Fig. 3) following the $\mathrm{AlCl}_{3}$ injections. In contrast, pretreatment with medium and high doses of BTL-I prevented these effects of $\mathrm{AlCl}_{3}$.

\section{Effect of $\mathrm{AlCl}_{3}$ on proinflammatory cytokines, $\mathrm{AChE}$ and GSH}

In addition to overt behavioral effects, $\mathrm{AlCl}_{3}$ treatment promoted the release of $\mathrm{IL}-1 \beta$ from the brain and peripheral tissue and TNF- $\alpha$ from brain, and BTL-I supplementation inhibited the release of IL-1 $\beta$ in the brain and peripheral, as well as the release of TNF in the brain $(F(4,10)=20.64, P<0.001$ for brain IL-1 $\beta$ in Fig. 4a; $F(4,10)=7.240, P<0.01$ for peripheral IL-1 $\beta$ in Fig. 4b; $F(4,10)=11.75, P<0.001$ for brain TNF-a in Fig. 4c). It's also noticed that BTL-I increased the peripheral TNF-a level $(F(4,10)=14.94, P<$ 0.001 in Fig. 4d).

Furthermore, paralleling their cognitive deficits in the T-maze, zebrafish treated with $\mathrm{AlCl}_{3}$ exhibited higher brain AChE activity, whereas both moderate and high doses of BTL- $\triangle$ dose-dependently inhibited AChE activity $(F(4,10)=4.474, P<0.05$ in Fig. 4 e). This is consistent with the fact that excessive AChE activity is closely related to memory deficits [45].

Besides, treatment with $\mathrm{AlCl}_{3}$ caused oxidant-antioxidant imbalance in the brain, $\mathrm{GSH}$, the key nonenzymatic antioxidant in the body, has important physiological functions, such as scavenging free radicals, detoxifying, promoting iron absorption or maintaining membrane integrity [46-50]. As GSH is a low molecular weight scavenger of $\mathrm{O}_{2}{ }^{-}, \mathrm{H}_{2} \mathrm{O}_{2}$ and so on, its content is an important indicator of the antioxidant capacity of the body [51]. Here, $\mathrm{AlCl}_{3}$ treatments decreased GSH levels in the fish brain ( $\mathrm{F}(4$, $10)=18.90, P<0.001$ in Fig. 4f). Compared with the model group, the BTL- $\bigotimes$ treatment groups did not show antioxidant activity since no higher GSH level was observed in them. However, they dosedependently increased GSH levels in zebrafish.

\section{Results of intestinal flora diversity analysis}

OTU is a hypothetical computational taxon (strain, species, genus, group, etc.) that has been set artificially to facilitate the analysis of phylogenetic or population genetics. Because of the conservatism of $16 \mathrm{~S}$ rDNA, the sequence obtained by sequencing can represent a species. To understand the composition of a species in a population sample, it is necessary to cluster the sequences. By clustering, the sequence is divided into many groups according to similarity, and one group is an OTU [52]. In this 
study, 15 samples were investigated, and the number of OTUs received by each sample was shown in Fig. 5a.

The Venn diagram is used to count the common and unique OTU numbers of multiple samples, which can intuitively show the similarity and overlap of the OTU number composition of environmental samples. Figure $5 \mathrm{~b}$ shows the differences in OTUs between the five groups. Different colors represent different groups, and the intersecting part is the OTU shared by adjacent groups. The OTUs in each group were as follows: Group B1 (model) 235; Group B2 (control) 213, Group B3 (25 mg/kg BTL-I + $\mathrm{AlCl}_{3}$ ) 233; Group B4 (50 mg/kg BTL-I + $\left.\mathrm{AlCl}_{3}\right)$ 229; and Group B5 (100 mg/kg BTL-I + $\left.\mathrm{AlCl}_{3}\right) 216$. The OTUs common between the model group and the other groups were as follows: 163 (Groups B1 and B2); 160 (Groups B1 and B3); 181 (Groups B1 and B4); 179 (Groups B1 and B5) (Fig. 5b).

In order to test the rationality of intestinal flora sequencing of samples, we constructed the rarefaction curves and rank abundance curves of intestinal flora according to the OTU numbers at different sequencing depths. The curve tends to be flat from 10000 reads, indicating that the sequencing data volume is adequate, and more data volume will only produce a small number of new OTUs (Fig. 6a). Rank-abundance curve can be used to explain abundance and evenness of species. In the horizontal direction, the abundance of species is reflected by the width of the curve (i.e., the higher the abundance of species the larger the range of the curve). The shape (smoothness) of the curve reflects the evenness of species in the sample (i.e., the flatter the curve, the more uniform the distribution of species). The results showed that the rank-abundance curve was smooth except for individual samples, indicating that the species distribution of each sample was evenness (Fig. 6b).

Alpha diversity can reflect the abundance and diversity of microbial communities, including Chao index, Ace index, Shannon index, Simpson index, etc. The Chao and Ace indices reflect the species richness, i.e., the number of species in the sample, without considering the abundance of each species. Shannon and Simpson indices reflect both species richness and species evenness in the community. The comparison between all the five groups showed that there was no significant total difference in bacterial diversity. However, Shannon and Simpson indices displayed relatively larger difference between model group and control group compared with the difference between control group and administration groups (Fig. 6c f).

The Beta diversity analysis was used to compare the differences in species diversity of the paired samples. The contents of each species in the samples were analyzed, and then the Beta diversity values among different samples were calculated.

NMDS method was a data analysis method that simplifies the research objects in multi-dimensional space to low-dimensional space for positioning, analysis and classification, while retaining the original relationship between objects. The degree of difference between samples was reflected by the distance between points. Four algorithms including Jaccard, Bray-Curtis, unweighted-Unifrac, and weighted-Unifrac were used for NMDS calculation. The NMDS based on Jaccard algorithm only considers whether the 
specific OTU existed in the sample, not its abundance. The NMDS based on Bray-Curtis algorithm considers both OTU varieties and abundances in samples. UniFrac analysis uses evolutionary information of sample sequences to compare whether the samples have significant microbial community differences in a particular evolutionary lineage. The unweighted-Unifrac method only considers whether the specific sequence appears in the community, not its abundance. The weighted-Unifrac method takes both existence and abundance into account. The results by Jaccard, unweighted-UniFrac, weightedUniFrac methods showed that there was no significant difference in OTU varieties or evolutionary lineage between the experimental groups, the control group and the model group (Fig. 7a, 7c, \& 7d). However, the results by Bray-Curtis method showed that there were significant differences in OTU abundance between the model group and the control group whereas no significant difference in OTU abundance between the experimental groups (except for $50 \mathrm{mg} / \mathrm{kg}$ group) and the control group (Fig. 7b).

Microbial diversity analysis showed that the intestinal flora of zebrafish included the following 12 major phyla: Proteobacteria, Firmicutes, Actinobacteria, Fusobacteria, Planctomycetes, Chlamydiae, Bacteroidetes, Chloroflexi, Tenericutes, Verrucomicrobia, Deinococcus-Thermus and Saccharibacteria. Among these, Proteobacteria, Firmicutes and Actinobacteria were the dominant bacteria at the phylum level (Fig. 8a). The abundances of Firmicutes in the gut of the model group were reduced, whereas those of Fusobacteria, Planctomycetes, Chlamydiae and Chloroflexi significantly increased, compared with those observed in the control group. In two experimental groups (administration of BTL- $\square 25 \mathrm{mg} / \mathrm{kg}$ and $100 \mathrm{mg} / \mathrm{kg}$ ), the abundances of Firmicutes significantly increased, whereas those of Fusobacteria and Chlamydiae significantly decreased compared with the model group, and basically returned to the same level as the control group. However, in the BTL- $\triangle$ treatment groups, there were almost no significant reversal effect on the increase of Planctomycetes and Chloroflexi abundance (Fig. 8c).

On genus level, a total of 30 major known taxa of intestinal flora were identified (Fig. 8b). The first 8 genera with inter-group abundance differences were respectively: Bacillus, Bosea, Cetobacterium, Alpinimonas, Singulisphaera, Phreatobacter, Mycobacterium, Candidatus-Microthrix (Fig. 8d). Compared with the control group, the abundance of Bacillus in the model group significantly decreased, while those of the other seven genera mostly increased significantly. In two BTL-囚 treatment groups $(25 \mathrm{mg} / \mathrm{kg}$ and $100 \mathrm{mg} / \mathrm{kg}$ ), the abundance of Bacillus had been elevated to nearly normal level, while those of Bosea and the other genera had mostly decreased significantly.

LEfSe was able to compare the taxa composition of multiple groups on different taxonomical levels, identify the taxa with significant inter-group differences in abundance (i.e., biomarkers), and exhibit their lineage relationship. The results in Fig. 9 showed the biomarkers with significant effects (LDA scores > 2) in each group, including 27 taxa in the model group (Cetobacterium in Fusobacteria, Bosea in Rhizobiales, Chlamydiales, Candidatus microthrix, Mycobacterium, etc.), 11 taxa in the control group (Bacillus in Firmicutes, Rhizobium rhizoryzae, etc.), 9 taxa in the low dose group ( $25 \mathrm{mg} / \mathrm{kg} \mathrm{BTL}-\mathrm{l})$ (Singulisphaera in Planctomycetes, Micromonospora, etc.), 10 taxa in the medium dose group (50 mg/kg BTL-I) (Clostridiaceae, Chloroflexi, Pseudoxanthobacter, etc.), and 2 taxa in the high dose group (100 $\mathrm{mg} / \mathrm{kg}$ BTL-I) (Gracilibacteraceae and Lutispora). 


\section{Prediction of ADMET and drug-likeness properties}

To obtain more information about the pharmacokinetic profile of BTL-I and whether it has the potential to become a drug, we used ADMETlab $2.0[43,44]$ to predict its ADMET and drug-likeness properties. The corresponding predicted results are presented in Table 1, and the physical properties of BTL-I are shown in Table S1 (see Supplementary data). The results demonstrated that the BTL-I possesses acceptable ADMET and drug-likeness properties in general. For example, results showed that BTL-I is active in both human intestinal absorption (HIA) and blood-brain barrier (BBB) penetration. It has acceptable safety profiles, generally performing well on most metrics (e.g., hERG blockers, Ames toxicity and carcinogenicity), and it is in harmony with Lipinski rule [53] and others (such as Pfizer rule [54] and golden triangle [55]), which indicates the drug-likeness properties of a compound. Unfortunately, BTL-I displayed some disadvantageous nature, such as a high risk of inhibiting CYP2C19, CYP2C9 and CYP3A4, and inducing liver injury. 
Table 1

ADMET and drug-likeness properties of BTL-I through online prediction tool of ADMETlab 2.0. (The table is located below line 394.)

\begin{tabular}{|lll|}
\hline Property & Value & Decision \\
\hline Absorption & & \\
\hline Caco-2 permeability & $-4.9 \mathrm{log} \mathrm{cm} / \mathrm{s}$ & \\
\hline Madin - Darby canine kidney cells (MDCK) permeability & $2 \mathrm{e}-05 \mathrm{~cm} / \mathrm{s}$ & \\
\hline P-glycoprotein (Pgp)-inhibitor & 0.023 & \\
\hline P-glycoprotein (Pgp)-substrate & 0.007 & \\
\hline Human intestinal absorption (HIA) & 0.008 & \\
\hline 20\% bioavailability (F20\%) & 0.059 & \\
\hline Distribution & & \\
\hline Plasma protein binding (PPB) & 0.987 & \\
\hline Volume distribution (VD) & $0.501 \mathrm{~L} / \mathrm{kg}$ & \\
\hline Blood-brain barrier (BBB) penetration & 0.027 & - \\
\hline The fraction unbound in plasms (Fu) & 0.012 & - \\
\hline Metabolism & & - \\
\hline CYP1A2-inhibitor & 0.381 & - \\
\hline CYP1A2-substrate & 0.536 & - \\
\hline CYP2C19-inhibitor & $0.179 \mathrm{~mL} / \mathrm{min} / \mathrm{kg}$ & - \\
\hline CYP2C19-substrate & 0.955 & - \\
\hline CYP2C9-inhibitor & 0.189 & - \\
\hline CYP2C9-substrate & 0.934 & - \\
\hline CYP2D6-inhibitor & 0.936 & - \\
\hline CYP2D6-substrate & & - \\
\hline CYP3A4-inhibitor & 0.973 & - \\
\hline CYP3A4-substrate & & - \\
\hline Excretion & & - \\
\hline Clearance & & - \\
\hline
\end{tabular}

excellent, ๑: medium, $\mathbf{0}$ : bad. 


\begin{tabular}{|c|c|c|}
\hline Property & Value & Decision \\
\hline The half-life $\left(T_{1 / 2}\right)$ & 0.371 & - \\
\hline \multicolumn{3}{|l|}{ Toxicity } \\
\hline hERG blockers & 0.023 & 0 \\
\hline $\begin{array}{l}\text { Human hepatotoxicity } \\
(\mathrm{H}-\mathrm{HT})\end{array}$ & 0.402 & 0 \\
\hline Drug induced liver injury (DILI) & 0.764 & ○ \\
\hline Ames toxicity & 0.106 & 0 \\
\hline Rat oral acute toxicity & 0.559 & 0 \\
\hline Maximum recommended daily dose (FDAMDD) & 0.283 & 0 \\
\hline Skin sensitization & 0.105 & 0 \\
\hline Carcinogenicity & 0.162 & 0 \\
\hline Eye corrosion & 0.003 & 0 \\
\hline Eye irritation & 0.146 & 0 \\
\hline Respiratory toxicity & 0.039 & 0 \\
\hline Property & Value & Decision \\
\hline \multicolumn{3}{|l|}{ Drug-likeness } \\
\hline MCE-18 [56] & 68.839 & 0 \\
\hline Lipinski rule [53] & Accepted (0 violation) & 0 \\
\hline Pfizer rule [54] & Accepted (0 violation) & 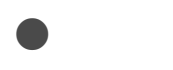 \\
\hline Golden triangle [55] & Accepted (0 violation) & 0 \\
\hline GSK rule [57] & Rejected (1 violation) & 0 \\
\hline
\end{tabular}

\section{Discussion}

Aluminum has been examined for its broad neurotoxic effects and close relationship with AD, which promote tau hyperphosphorylation, aggregation, and neurofibrillary tangle formation in AD brain (via activating tau kinases CDK5 and GSK3 3 ), accumulate in microglia and induce proinflammatory cytokines, bind to $A \beta$ and induce its aggregation, stimulate iron-induced membrane lipid peroxidation and oxidative damage, decrease the activity of antioxidant enzymes, interact with AChE on y-peripheral site to 
enhance enzymatic activity resulting in reduced neurotransmission $[12,58,59]$. Furthermore, activated AChE can deteriorate A $\beta$ aggregation, decrease BDNF expression [58], and further promote oxidative stress and neuroinflammation through a 'cholinergic anti-inflammatory pathway' (CAIP) via a7 nicotinic acetylcholine receptors $[59,60]$. Besides, in many reports on Aluminum induced $A D$ or toxicity models, the alteration of host gut microbiota had been observed [61, 62].

The present study has established the zebrafish model of subchronic inflammation induced by acute i.p. $\mathrm{AlCl}_{3}$ administration, resulting in subchronic peripheral and central inflammatory responses and enhanced oxidative stress and AChE activity in the brain. On behavioral level, administration of $\mathrm{AlCl}_{3}$ strongly impaired spatial and contextual memory of zebrafish in the T-maze test. On gut microbiota level, high-throughput sequencing results showed that the intestinal flora of zebrafish was dramatically disturbed by acute $\mathrm{AlCl}_{3}$ administration. Collectively, these findings are generally consistent with previous evidence that $\mathrm{AlCl}_{3}$ induce memory deficits in both humans and animals, including zebrafish, and change intestinal flora [61-63]. In contrast, BTL- $\triangle$ co-administration reversed these induced memory deficits and microbiota imbalance, indicating potential neuroprotective role of this drug.

In the present study, acute central and peripheral inflammation was characterized by release of pro-

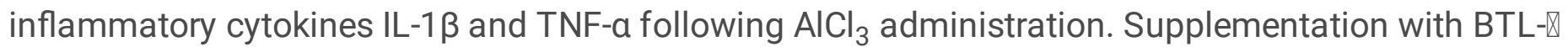
potently inhibited acute central and peripheral inflammation in the $\mathrm{AlCl}_{3}$-treated zebrafish. Mounting evidence implicates BTL-囚 in multi-targeted neuroprotective activity against oxidative stress, neuroinflammation and neuronal apoptosis, as well as in nerve growth without inducing cytotoxicity [2226]. Here, we found that $B T L-\square$ also prevents cognitive deficits (induced in zebrafish by $\mathrm{AlCl}_{3}$ ) and exerts neuroprotective effects in this zebrafish model.

Previously studies have shown that hepatotoxicity and liver injury potentially induce inflammation [64, $65]$ and lead to increased levels of inflammatory markers such as IL-1 $\beta$ and TNF-a $[66,67]$ In this study, we noted that peripheral TNF-a levels were elevated after BTL-I administration, presumably due to BTL-I's potential hepatotoxicity and liver injury effects. This is suggested by ADMET analysis (Table 1). But It remains unclear why peripheral IL-1 $\beta$ and TNF-a behave differently after BTL-I administration, which may be attributable to the different mechanisms, and this needs further investigations.

The inhibition of brain AChE elevates ACh levels, and hence positively affects cognitive function in rats $[59,68]$. Subchronic exposure of zebrafish to $\mathrm{AlCl}_{3}$ or i.p. injection of $\mathrm{AlCl}_{3}$ in mice enhance brain $\mathrm{AChE}$ activity [37]. In line with this, our results show that i.p. injection of $\mathrm{AlCl}_{3}$ also elevate $\mathrm{AChE}$ activity in

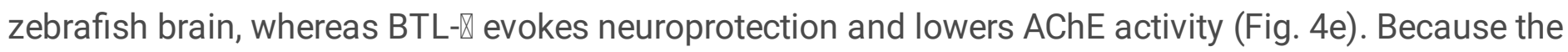
thin-layer chromatography bioautography shows that BTL- $\triangle$ does not inhibit AChE catalytic activity (data not shown), this compound seems to indirectly decrease zebrafish AChE activity here, likely involving other molecular pathways.

Furthermore, oxidative stress involves the excessive production of ROS and reactive nitrogen species (RNS) [69], and may result in tissue damage. GSH is the most important nonenzymatic antioxidant, 
whose neuroprotective role in the brain is critical against oxidative damage caused by catecholamine oxidation or lipid peroxidation [70]. In the present study, GSH levels markedly decreased, $24 \mathrm{~h}$ after the $\mathrm{AlCl}_{3}$ administration. With the pretreatment of BTL-I at the dose of $25 \mathrm{mg} / \mathrm{kg}$ and $50 \mathrm{mg} / \mathrm{kg}$, the GSH levels of the zebrafish were even lower than the model group. But, when the dose rose to $100 \mathrm{mg} / \mathrm{kg}$, the GSH content increased to the same level as model group though it was still lower than the control group. BTL-I seemed to display doubtful antioxidant effect via GSH. The lack of significant antioxidant effects of BTL-I relative to the model group may be due to the limited sample size and the resulting low statistical power. Although it may also suggest that the antioxidant mechanism of action of BTL-I may exist elsewhere. Further study with larger sample sizes and better designs are warranted to testify and explain this complicated phenomenon for a solid conclusion.

Intestinal flora plays a crucial role in the stability and balance of intestinal microecological environment, and the composition of human intestinal microbial community remains basically stable after the age of 3 years [71]. In recent years, a growing number of studies had shown that specific intestinal flora play important role in neuroprotection and their disorders were closely related to neurodegenerative diseases including $A D[15,16,72]$. Some reports indicated that, in the gut of healthy human or animals, there are higher population of Gram-positive $\left(\mathrm{G}^{+}\right)$bacteria including Firmicutes and Actinobacteria and lower Gram-negative $\left(\mathrm{G}^{-}\right)$bacteria like Bacteroidetes on phylum level $[15,16]$. At family or genus level, Some $\mathrm{G}^{+}$ taxa like Bacillus, Eubacterium, Clostridiaceace in Firmicutes and Bifidobacterium in Actinobacteria show higher abundance in healthy individuals and benefit their hosts through different mechanisms including reducing leakage of gut by the protection of biofilm, inhibiting inflammation, anti-oxidation, reducing $A \beta$ deposition and transferation from gut to brain, etc $[15,16,73]$. On the contrary, some $\mathrm{G}^{-}$taxa like Bacteriodes, Blautia, Escherichia coli, Shigella, Chlamydia, Fusobacterium, etc., are closely and positively correlated with AD mainly involving the activation of systematic inflammation by their enriched LPS in cell wall, the invasion of proinflammatory cytokines, LPS, and even bacteria into blood circulation system and brain, inducing $A \beta$ deposition and tau phosphorylation $[15,16,72,73]$.

In the present study, the control group zebrafishes host higher $\mathrm{G}^{+}$bacteria (Firmicutes on phylum level and predominantly Bacillus on genus level) than $\mathrm{AlCl}_{3}$ injured model group with memory impairment, while the model group zebrafishes have much less $\mathrm{G}^{+}$bacteria than the control group but significantly more $\mathrm{G}^{-}$bacteria including Cetobacterium (in family of Fusobacteriaceae) and Chlamydiales (on order level). This is highly consistent with the previous studies especially the report on the benefits of Bacillus subtilis in delaying neurodegeneration and behavior impairment in the AD model Caenorhabditis elegans and the report on the negative effect of $\mathrm{G}^{-}$bacteria including Fusobacterium and Chlamydia [72-74].

Generally, the pretreatment of BTL-I maintained the dominance of $\mathrm{G}^{+}$bacteria $\mathrm{VS} \mathrm{G}^{-}$ones in the gut of zebrafishes when facing the impact of Aluminum. However, the dose levels exerted different influence. In low and high dose groups, the abundances of Bacillus have kept at high levels close to that of control group and the abundances of G- bacteria were much lower. Additionally, in low dose group, another $\mathrm{G}^{+}$ bacteria Micromonospora in phylum of Actinobacteria was recognized as a biomarker, hinting its 
possible positive role, when compared with a report [16] about Actinobacteria. Likewise, in high dose group, $\mathrm{G}^{+}$bacteria Lutispora in family of Gracilibacteriaceae and order of Clostridiales was also biomarker. Considering the report on the strongly negative correlation of Clostridiaceae [16] with AD biomarkers in cerebrospinal fluid, we speculate that Lutispora may also have some benefit in neuroprotection.

It's intriguing that the middle dose group did not possess high abundance of Bacillus. This discrepancy may be attributable to a non-linear relationship of BTL-I and Bacillus, more concentration gradients of BTL-I will be set in the further study to explore this relationship. However, $\mathrm{G}^{+}$bacteria Clostridiaceae was found to be the key biomarker of this group; besides, $\mathrm{G}^{-}$bactereia Chloroflexi bacteria was its another key biomarker but bacteria in this phylum have no LPS in cell walls [75]. These may help to explain the behavioral improvement of this group.

Our study suggests that administration of marine fungal metabolite BTL-I prior to $\mathrm{AlCl}_{3}$ injection may be able to maintain the predominance of beneficial $\mathrm{G}^{+}$bacteria in the gut of zebrafish to resist the acute injury of Aluminum, the related inflammation and $A D$ pathology. The detailed mechanisms of intestinal flora regulation and the treatment effect on $\mathrm{AlCl}_{3}$ induced chronic $A D$ model need to be further investigated for BTL-I in future.

The early evaluation of ADMET and drug-likeness properties of drug candidates are highly significant, as many drugs have been withdrawn in clinical trials and even in the marketing process due to unacceptable pharmacokinetics properties [76-78]. In this sense, the prediction of ADMET and drug-likeness properties of drug candidates have received extensive attention. And numerous tools have been developed such as ADMETlab [79] admetSAR [80] and SwissADME [81] In this study, the in silico prediction with ADMETlab suggested that BTL-I caters to the majority of the ADMET properties, drug-likeness profiles such as the typical Lipinski rule with 0 violation, and possess good properties in crossing BBB. Such features render it a promising drug candidate for NDs, since overcome BBB penetration is essential for the drugs of NDs $[82,83]$ While it should be noted that BTL-I was predicted to be at high risk of liver injury, which requires further confirmation and assessment and may provide clues for structural optimization.

\section{Conclusions}

This study showed that BTL-I dose-dependently ameliorated $\mathrm{AlCl}_{3}$-induced cognitive deficits in zebrafish, reversed the elevation of $\mathrm{AlCl}_{3}$-induced central and peripheral proinflammatory cytokine levels and the increase of brain AChE activity, contributed to maintain the predominance of beneficial Gram-positive bacteria in the intestinal flora of zebrafish, which was challenged by $\mathrm{AlCl}_{3}$. The in-silico analysis indicated that BTL-I exhibits acceptable drug-likeness and ADMET profiles. In summary, BTL-I has the potential as therapeutic agent for preventing CNS deficits caused by inflammation, neurotoxicity, and gut flora imbalance. 


\section{Abbreviations}

AChE

Acetylcholinesterase

AD

Alzheimer's disease

ADMET

Absorption, distribution, metabolism, excretion, and toxicity

$A \beta$

$\beta$-amyloid peptide

BTL-I

Butyrolactone I

BTLs

Butyrolactones

CAIP

Cholinergic anti-inflammatory pathway

\section{CDK 5}

Cyclin-dependent kinase 5

CNS

Central nervous system

coX-2

Cyclooxygenase-2

GSH

Glutathione

IL-1 $\beta$

Interleukin-1 $\beta$

KW

Kruskal-Wallis

LDA

Linear discriminant analysis

NDs

Neurodegenerative disorders

NMDS

Non-metric multidimensional scaling graphs

PD

Parkinson's disease

RNS

Reactive nitrogen species

ROS

Reactive oxygen species 
TNF-a

Tumor necrosis factor-a

\section{Declarations}

\section{Consent for publication}

Not applicable.

\section{Availability of data and materials}

All data generated or analyzed during this study are included in this published article and its supplementary information file. The datasets used and/or analyzed during the current study are available from the primary author on reasonable request.

\section{Competing interests}

The authors declare that they have no competing interests.

\section{Funding}

This work was supported by the Yangfan Talent Project of Guangdong Province (201433009), Natural Science Foundation of Guangdong Province (2018A030307046), Basic Research Project of Shenzhen Science and Technology Innovation Commission (JCYJ20190813105005619), Shenzhen Dapeng New District Industrial Development Fund (PT201901-05), Shenzhen Dapeng New District Scientific and Technological Research and Development Fund (KJYF202001-07), National Natural Science Foundation (21807015), Marine Economy Promotion Fund of Guangdong Province ([2019]015), Innovation and Development Project about Marine Economy Demostration of Zhanjiang City (XM-202008-01B1).

\section{Authors' contributions}

YN performed the zebrafish experiment, analyzed data and wrote the original draft. YJ, JL, YL and XM prepared the compound sample and assisted in zebrafish experiments. $Y Z$ designed and guided the experiments, gave critical comments for the research, and revised the paper. ZY, LZ, ZQ, PH, AVK and CS gave critical comments for the research and polished the paper. All the authors have read and approved the final manuscript.

\section{Acknowledgements}

Not applicable.

\section{Ethics approval and consent to participate}

The procedures were previously approved by the Animal Ethics Committee of Guangdong Ocean University, numbered 2019-11-23-2. 


\section{References}

1. Thomas B, Beal MF. Parkinson's disease. Hum Mol Genet. 2007;16:R183-R94. https://doi.org/10.1093/hmg/ddm159.

2. Whitehouse PJ, Price DL, Struble RG, Clark AW, Coyle JT, Delon MR. Alzheimer's disease and senile dementia: loss of neurons in the basal forebrain. Sci. 1982;215:1237-39. https://doi.org/10.1126/science.7058341.

3. Mckhann G, Drachman D, Folstein M, Katzman R, Price D, Stadlan EM. Clinical diagnosis of Alzheimer disease: report of NINCDS-ADRDA work group under the auspices of department of health and human service task force on Alzheimer's disease. Neurol. 1984;34:939-44. https://doi.org/10.1212/WNL.34.7.939.

4. Olanow CW, Tatton WG. Etiology and pathogenesis of Parkinson's disease. Annu Rev Neurosci. 1999;22:123-44. https://doi.org/10.1002/mds.23732.

5. Bachurin SO, Bovina EV, Ustyugov AA. Drugs in clinical trials for Alzheimer's disease: the major trends. Med Res Rev. 2017;37:1186-225. https://doi.org/10.1002/med.21434.

6. Honig LS, Vellas B, Woodward M, Boada M, Bullock R, Borrie M, Hager K, Andreasen N, Scarpini E, Liu-Seifert $\mathrm{H}$, et al. Trial of solanezumab for mild dementia due to Alzheimer's disease. N Engl J Med. 2018;378:321-30. https://doi.org/10.1007/s00415-018-9018-1.

7. Ransohoff RM. How neuroinflammation contributes to neurodegeneration. Sci. 2016;353:777-83. https://doi.org/10.1126/science.aag2590.

8. Kumar DK, Choi SH, Washicosky KJ, Eimer WA, Tucker S, Ghofrani J, Lefkowitz A, McColl G, Goldstein LE, Tanzi RE, Moir RD. Amyloid- $\beta$ peptide protects against microbial infection in mouse and worm models of Alzheimer's disease. Sci Transl Med. 2016;8:340ra72. http://dx.doi.org/10.1126/scitranslmed.aaf1059.

9. Uttara B, Singh A, Zamboni P, Mahajan R. Oxidative stress and neurodegenerative diseases: a review of upstream and downstream antioxidant therapeutic options. Curr Neuropharmacol. 2009;7:65-74. https://doi.org/10.2174/157015909787602823.

10. Heneka MT, Carson MJ, El Khoury J, Landreth GE, Brosseron F, Feinstein DL, Jacobs AH, Wyss-Coray T, Vitorica J, Ransohoff RM, et al. Neuroinflammation in Alzheimer's disease. Lancet Neurol. 2015;14:388-405. https://doi.org/10.1016/S1474-4422(15)70016-5.

11. Chen WW, Zhang X, Huang WJ. Role of neuroinflammation in neurodegenerative diseases. Mol Med Rep. 2016;13:3391-6. https://doi.org/10.3892/mmr.2016.4948.

12. Huat TJ, Camats-Perna J, Newcombe EA, Valmas N, Kitazawa M, Medeiros R. Metal toxicity links to Alzheimer's disease and neuroinflammation. J Mol Biol. 2019;431:1843-68. https://doi.org/10.1016/j.jmb.2019.01.018.

13. Leszek J, Barreto GE, Gasiorowski K, Koutsouraki E, Avila-Rodrigues M, Aliev G. Inflammatory mechanisms and oxidative stress as key factors responsible for progression of neurodegeneration: 
role of brain innate immune system. CNS Neurol Disord: Drug Targets. 2016;15:329-36. http://dx.doi.org/10.2174/1871527315666160202125914.

14. Song $C$, Zhang Y, Dong YL. Acute and subacute IL-1 $\beta$ administrations differentially modulate neuroimmune and neurotrophic systems: possible implications for neuroprotection and neurodegeneration. J Neuroinflammation. 2013;10:59. https://doi.org/10.1186/1742-2094-10-59.

15. Cattaneo A, Cattane N, Galluzzi S, Provasi S, Frisoni GB. Association of brain amyloidosis with proinflammatory gut bacterial taxa and peripheral inflammation markers in cognitively impaired elderly. Neurobiol Aging. 2017;49:60-8. http://dx.doi.org/10.1016/j.neurobiolaging.2016.08.019.

16. Vogt NM, Kerby RL, Dill-Mcfarland KA, Harding SJ, Merluzzi AP, Johnson SC, Carlsson CM, Asthana S, Zetterberg $\mathrm{H}$, Blennow K, et al. Gut microbiome alterations in Alzheimer's disease. Sci Rep. 2017;7:13537. https://doi.org/10.1038/s41598-017-13601-y.

17. Mattson MP. Pathways towards and away from Alzheimer's disease. Nat. 2004;430:631-9. https://doi.org/10.1038/nature02621.

18. Chiti F, Dobson CM. Protein misfolding, amyloid formation, and human disease: a summary of progress over the last decade. Annu Rev Biochem. 2017;86:27-68. https://doi.org/10.1146/annurevbiochem-061516-045115.

19. Shie FS, Ling Z. Therapeutic strategy at the crossroad of neuroinflammation and oxidative stress in age-related neurodegenerative diseases. Expert Opin Ther Pat. 2007;17:419-28. https://doi.org/10.1517/13543776.17.4.419.

20. Yuan L, Huang WZ, Zhou K, Wang YD, Dong W, Du G, Gao XM, Ma YH, Hu QF. Butyrolactones derivatives from the fermentation products of a plant entophytic fungus Penicillium oxalicum. Nat Prodt Res. 2015;29:1914-9. https://doi.org/10.1080/14786419.2015.1013473.

21. Schimmel TG, Coffman AD, Parsons SJ. Effect of butyrolactone I on the producing fungus, Aspergillus terreus. Appl Environ Microbiol. 1998;64:3707-12.

https://doi.org/10.1128/AEM.64.10.3707-3712.1998.

22. Zhang YY, Zhang Y, Yao YB, Lei XL, Qian ZJ. Butyrolactone-I from coral-derived fungus Aspergillus terreus attenuates neuro-inflammatory response via suppression of NF-KB pathway in BV-2 cells. Mar Drugs. 2018;16:202. https://doi.org/10.3390/md16060202.

23. Alvarez A, Toro R, Caceres A, Maccioni RB. Inhibition of tau phosphorylating protein kinase cdk5 prevents beta-amyloid-induced neuronal death. Febs Lett. 1999;459:421-6. https://doi.org/10.1016/S0014-5793(99)01279-X.

24. Dobashi Y, Shoji M, Kitagawa M, Noguchi T, Kameya T. Simultaneous suppression of cdc2 and cdk2 activities induces neuronal differentiation of PC12 cells. J Biol Chem. 2000;275:12572-80. https://doi.org/10.1074/jbc.275.17.12572.

25. Inokoshi J, Katagiri M, Arima S, Tanaka H, Hayashi M, Kim YB, Furumai R, Yoshida M, Horinouchi S, Omura S. Neuronal differentiation of neuro 2a cells by inhibitors of cell cycle progression, trichostatin A and butyrolactone I. Biochem Biophys Res Commun. 1999;256:372-6. https://doi.org/10.1006/bbrc.1999.0316. 
26. Quintanilla RA, Orellana DI, Gonzalez-Billault C, Maccioni RB. Interleukin-6 induces Alzheimer-type phosphorylation of tau protein by deregulating the cdk5/p35 pathway. Exp Cell Res. 2004;295:24557. https://doi.org/10.1016/j.yexcr.2004.01.002.

27. Pichler FB, Laurenson S, Williams LC, Dodd A, Copp BR, Love DR. Chemical discovery and global gene expression analysis in zebrafish. Nat Biotechnol. 2003;21:879-83. https://doi.org/10.1038/nbt852.

28. Hertog JD. Chemical genetics: drug screens in zebrafish. Biosci Rep. 2005;25:289-97. https://doi.org/10.1007/s10540-005-2891-8.

29. Guo S. Molecular and therapeutic insights from model systems: Insights from zebrafish PD models and their potentials for identifying novel drug targets and therapeutic compounds. In: Richard N, Serge P, editors. Parkinson's Disease. Pittsburgh: Academic Press; 2008. https://doi.org/10.1016/B978-0-12-374028-1.00023-3. p. 309 - 19.

30. Trede NS, Zapata A, Zon LI. Fishing for lymphoid genes. Trends Immunol. 2001;22:302-7. https://doi.org/10.1016/S1471-4906(01)01939-1.

31. Giudicelli F, Ozbudak EM, Wright GJ, Lewis J. Setting the tempo in development: an investigation of the zebrafish somite clock mechanism. Plos Biol. 2007;5:1309-23. https://doi.org/10.1371/journal.pbio.0050150.

32. Guo S. Linking genes to brain, behavior and neurological diseases: what can we learn from zebrafish? Genes Brain Behav. 2004;3:63-74. https://doi.org/10.1046/j.1601-183X.2003.00053.x.

33. Ninkovic J, Bally-Cuif $L$. The zebrafish as a model system for assessing the reinforcing properties of drugs of abuse. Methods. 2006;39:262-74. https://doi.org/10.1016/j.ymeth.2005.12.007.

34. Zhdanova IV, Wang SY, Leclair OU, Danilova NP. Melatonin promotes sleep-like state in zebrafish. Brain Res. 2001;903:263-8. https://doi.org/10.1016/S0006-8993(01)02444-1.

35. Mathiyazahan DB, Thenmozhi AJ, Manivasagam T. Protective effect of black tea extract against aluminium chloride-induced Alzheimer's disease in rats: a behavioural, biochemical and molecular approach. J Funct Foods. 2015;16:423-35. https://doi.org/10.1016/j.jff.2015.05.001.

36. Rather MA, Justin-Thenmozhi A, Manivasagam T, Saravanababu C, Guillemin GJ, Essa MM. Asiatic acid attenuated aluminum chloride-induced tau pathology, oxidative stress and apoptosis via AKT/GSK-3 beta signaling pathway in Wistar rats. Neurotoxic Res. 2019;35:955-68. https://doi.org/10.1007/s12640-019-9999-2.

37. Senger MR, Seibt KJ, Ghisleni GC, Dias RD, Bogo MR, Bonan CD. Aluminum exposure alters behavioral parameters and increases acetylcholinesterase activity in zebrafish (Danio rerio) brain. Cell Biol Toxicol. 2011;27:199-205. https://doi.org/10.1007/s10565-011-9181-y.

38. Westerfield M. The zebrafish book: A guide for the laboratory use of zebrafish (Danio rerio). 5rd ed. Eugene: University of Oregon Press; 2007.

39. Grush J, Noakes DLG, Moccia RD. The efficacy of clove oil as an anesthetic for the zebrafish, Danio rerio (Hamilton). Zebrafish. 2004;1:46-53. https://doi.org/10.1089/154585404774101671. 
40. Darland T, Dowling JE. Behavioral screening for cocaine sensitivity in mutagenized zebrafish. Proc Natl Acad Sci USA. 2001;98:11691-6. https://doi.org/10.1073/pnas.191380698.

41. Williams FE, White $D$, Messer WS. A simple spatial alternation task for assessing memory function in zebrafish. Behav Processes. 2002;58:125-32. https://doi.org/10.1016/S0376-6357(02)00025-6.

42. Rishitha N, Muthuraman A. Therapeutic evaluation of solid lipid nanoparticle of quercetin in pentylenetetrazole induced cognitive impairment of zebrafish. Life Sci. 2018;199:80-7. https://doi.org/10.1016/j.lfs.2018.03.010.

43. Jiang DJ, Lei TL, Wang Z, Shen C, Cao DS, Hou TJ. ADMET evaluation in drug discovery. 20. Prediction of breast cancer resistance protein inhibition through machine learning. J Cheminf. 2020;12:16. https://doi.org/10.1186/s13321-020-00421-y.

44. Xiong G, Wu Z, Yi J, Fu L, Yang Z, Hsieh C, Yin M, Zeng X, Wu C, Lu A, et al. ADMETlab 2.0: an integrated online platform for accurate and comprehensive predictions of ADMET properties. Nucleic Acids Res. 2021. https://doi.org/10.1093/nar/gkab255.

45. Giacobini E, Spiegel R, Enz A, Veroff AE, Cutler NR. Inhibition of acetyl- and butyryl-cholinesterase in the cerebrospinal fluid of patients with Alzheimer's disease by rivastigmine: correlation with cognitive benefit. J Neural Transm. 2002;109:1053-65. https://doi.org/10.1007/s007020200089.

46. Grimble RF: The effects of sulfur amino acid intake on immune function in humans. $J$ Nutr 2006, 136:1660s-5s. https://doi.org/10.1093/jn/136.6.1660s.

47. Gu M, Owen AD, Toffa SEK, Cooper JM, Schapira AHV. Mitochondrial function, GSH and iron in neurodegeneration and Lewy body diseases. J Neurol Sci. 1998;158:24-9. https://doi.org/10.1016/S0022-510X(98)00095-1.

48. Hashimoto K, Takasaki W, Yamoto T, Manabe S, Sato I, Tsuda S. Effect of glutathione (GSH) depletion on DNA damage and blood chemistry in aged and young rats. J Toxicol Sci. 2008;33:4219. https://doi.org/10.2131/jts.33.421.

49. Schettler V, Wieland E, Methe H, Schuff-Werner P, A MG. Oxidative stress during dialysis: effect on free radical scavenging enzyme (FRSE) activities and glutathione (GSH) concentration in granulocytes. Nephrol Dial Transplant. 1998;13:2588-93. https://doi.org/10.1093/ndt/gfl351.

50. Sutton RH. Effect of eperythrozoon ovis infection on the reductive potential of sheep erythrocytes. Vet Parasitol. 1979;5:11-5. https://doi.org/10.1016/0304-4017(79)90035-9.

51. Zang L, He H, Xu Q, Yu Y, Zheng N, Liu W, Hayashi T, Tashiro SI, Onodera S, Ikejima T. Reactive oxygen species $\mathrm{H}_{2} \mathrm{O}_{2}$ and $\cdot \mathrm{OH}$, but not $\mathrm{O}_{2}$. ${ }^{-}$promote oridonin-induced phagocytosis of apoptotic cells by human histocytic lymphoma U937 cells. Int Immunopharmacol. 2013;15:414-23. https://doi.org/10.1016/j.intimp.2013.01.004.

52. Wooley JC, Godzik A, Friedberg I, Bourne PE. A primer on metagenomics. Plos Comput Biol. 2010;6:e1000667. https://doi.org/10.1371/journal.pcbi.1000667.

53. Lipinski CA, Lombardo F, Dominy BW, Feeney PJ. Experimental and computational approaches to estimate solubility and permeability in drug discovery and development settings. Adv Drug Delivery Rev. 2001;46:3-26. https://doi.org/10.1016/S0169-409X(00)00129-0. 
54. Hughes JD, Blagg J, Price DA, Bailey S, Decrescenzo GA, Devraj RV, Ellsworth E, Fobian YM, Gibbs $\mathrm{ME}$, Gilles RW, et al. Physiochemical drug properties associated with in vivo toxicological outcomes. Bioorg Med Chem Lett. 2008;18:4872-5. https://doi.org/10.1016/j.bmcl.2008.07.071.

55. Johnson TW, Dress KR, Edwards M. Using the golden triangle to optimize clearance and oral absorption. Bioorg Med Chem Lett. 2009;19:5560-4. https://doi.org/10.1016/j.bmcl.2009.08.045.

56. Ivanenkov YA, Zagribelnyy BA, Aladinskiy VA. Are we opening the door to a new era of medicinal chemistry or being collapsed to a chemical singularity? J Med Chem. 2019;62:10026-43. https://doi.org/10.1021/acs.jmedchem.9b00004.

57. Gleeson MP. Generation of a set of simple, interpretable ADMET rules of thumb. J Med Chem. 2008;51:817-34. https://doi.org/10.1021/jm701122q.

58. Auti ST, Kulkarni YA. Neuroprotective effect of cardamom oil against aluminum induced neurotoxicity in rats. Front Neurol. 2019;10:399. https://doi.org/10.3389/fneur.2019.00399.

59. Tabet N. Acetylcholinesterase inhibitors for Alzheimer's disease: anti-inflammatories in acetylcholine clothing! Age Ageing. 2006;35:336-8. https://doi.org/10.1093/ageing/afl027.

60. Benfante R, Lascio SD, Cardani S, Fornasari D. Acetylcholinesterase inhibitors targeting the cholinergic anti-inflammatory pathway: a new therapeutic perspective in aging-related disorders. Aging: Clin Exp Res. 2021;33:823-34. https://doi.org/10.1007/s40520-019-01359-4.

61. Yu L, Qiao N, Li T, Yu R, Chen W. Dietary supplementation with probiotics regulates gut microbiota structure and function in Nile tilapia exposed to aluminum. PeerJ. 2019;7:e6963. https://doi.org/10.7717/peerj.6963.

62. Weng MH, Chen SY, Li ZY, Yen GC. Camellia oil alleviates the progression of Alzheimer's disease in aluminum chloride-treated rats. Free Radicals Biol Med. 2020;152:411-21. https://doi.org/10.1016/j.freeradbiomed.2020.04.004.

63. White DM, Longstreth WT, Rosenstock L, Claypoole KHJ, Townes BD. Neurologic syndrome in 25 workers from an aluminum smelting plant. Arch Intern Med. 1992;152:1443-8. https://doi.org/10.1001/archinte.152.7.1443.

64. Weber A, Boger R, Vick B, Urbanik T, Haybaeck J, Zoller S, Teufel A, Krammer PH, Opferman JT, Galle PR, et al. Hepatocyte-specific deletion of the antiapoptotic protein myeloid cell leukemia-1 triggers proliferation and hepatocarcinogenesis in mice. Hepatol. 2010;51:1226-36. https://doi.org/10.1002/hep.23479.

65. Folk A, Cotoraci C, Balta C, Suciu M, Herman H, Boldura OM, Dinescu S, Paiusan L, Ardelean A, Hermenean A. Evaluation of hepatotoxicity with treatment doses of flucytosine and amphotericin $B$ for invasive fungal infections. BioMed Res Int. 2016;2016:1-9. https://doi.org/10.1155/2016/5398730.

66. Jaeschke H, Gores GJ, Cederbaum Al, Hinson JA, Pessayre D, Lemasters JJ. Mechanisms of hepatotoxicity. Toxicol Sci. 2002;65:166-76. https://doi.org/10.1093/toxsci/65.2.166.

67. Davies C, Dey N, Negrette OS, Parada LA, Basombrio MA, Garg NJ. Hepatotoxicity in mice of a novel anti-parasite drug candidate hydroxymethyInitrofurazone: a comparison with Benznidazole. PLOS 
Neglected Trop Dis. 2014;8:e3231. https://doi.org/10.1371/journal.pntd.0003231.

68. Santos D, Milatovic D, Andrade V, Batoreu MC, Aschner M, Santos APMD. The inhibitory effect of manganese on acetylcholinesterase activity enhances oxidative stress and neuroinflammation in the rat brain. Toxicol. 2012;292:90-8. https://doi.org/10.1016/j.tox.2011.11.017.

69. Bhat AH, Dar KB, Anees S, Zargar MA, Masood A, Sofi MA, Ganie SA. Oxidative stress, mitochondrial dysfunction and neurodegenerative diseases; a mechanistic insight. Biomed Pharmacother 2015:101-10. https://doi.org/10.1016/j.biopha.2015.07.025.

70. Effect of buthionine sulfoximine, a synthesis inhibitor of the antioxidant glutathione,on the murine nigrostriatal neurons\&nbsp. J Neurochem 2002, 67:2164-71. https://doi.org/10.1046/j.14714159.1996.67052164.x.

71. Rodríguez JM, Murphy K, Stanton C, Ross RP, Kober Ol, Juge N, Avershina E, Rudi K, Narbad A, Jenmalm MC, et al. The composition of the gut microbiota throughout life, with an emphasis on early life. Microb Ecol Health Dis. 2015;26:26050. https://doi.org/10.3402/mehd.v26.26050.

72. Stojkovi D, Kosti M, Smiljkovi M, Aleksi M, Vasiljevi P, Nikoli M, Sokovi M. Linking antimicrobial potential of natural products derived from aquatic organisms and microbes involved in Alzheimer's disease - A review. Curr Med Chem. 2020;27:4372-91. https://doi.org/10.2174/0929867325666180309103645.

73. Cogliati S, Clementi V, Francisco M, Crespo C, Grau R. Bacillus subtilis delays neurodegeneration and behavioral impairment in the Alzheimer's disease model Caenorhabditis elegans. J Alzheimer's dis. 2020;73:1035-52. https://doi.org/10.3233/JAD-190837.

74. Hill JM, Clement C, Pogue Al, Bhattacharjee S, Zhao Y, Lukiw WJ. Pathogenic microbes, the microbiome, and Alzheimer's disease (AD). Front Aging Neurosci. 2014;6:127. https://doi.org/10.3389/fnagi.2014.00127.

75. Garrity GM, Holt JG, Castenholz RW, Pierson BK, Keppen OI, Gorlenko VM: Phylum BVI. Chloroflexi phy. nov. In Bergey's Manual® of Systematic Bacteriology: Volume One: The Archaea and the Deeply Branching and Phototrophic Bacteria. Edited by Boone DR, Castenholz RW, Garrity GM. New York: Springer New York; 2001: 427 - 46.

76. Zanni R, Garcia-Domenech R, Galvez-Llompart M, Galvez J. Alzheimer: a decade of drug design. Why molecular topology can be an extra edge? Curr Neuropharmacol. 2018;16:849-64. https://doi.org/10.2174/1570159X15666171129102042.

77. Regitz-Zagrosek V, Oertelt-Prigione S, Prescott E, Franconi F, Gerdts E, Foryst-Ludwig A, Maas AH, Kautzky-Willer A, Knappe-Wegner D, Kintscher U, et al. Gender in cardiovascular diseases: impact on clinical manifestations, management, and outcomes. Eur Heart J. 2016;37:24-34. https://doi.org/10.1093/eurheartj/ehv598.

78. Allen JA, Roth BL. Strategies to discover unexpected targets for drugs active at $\mathrm{G}$ protein-coupled receptors. Annu Rev Pharmacol Toxicol. 2011;51:117-44. https://doi.org/10.1146/annurevpharmtox-010510-100553. 
79. Dong J, Wang NN, Yao ZJ, Zhang L, Cheng Y, Ouyang D, Lu AP, Cao DS. ADMETlab: a platform for systematic ADMET evaluation based on a comprehensively collected ADMET database. J Cheminf. 2018;10:29. https://doi.org/10.1186/s13321-018-0283-x.

80. Yang H, Lou C, Sun L, Li J, Cai Y, Wang Z, Li W, Liu G, Tang Y. admetSAR 2.0: web-service for prediction and optimization of chemical ADMET properties. Bioinf. 2019;35:1067-9. https://doi.org/10.1093/bioinformatics/bty707.

81. Daina A, Michielin O, Zoete V. SwissADME: a free web tool to evaluate pharmacokinetics, druglikeness and medicinal chemistry friendliness of small molecules. Sci Rep. 2017;7:42717. https://doi.org/10.1038/srep42717.

82. Ramalho MJ, Sevin E, Gosselet F, Lima J, Coelho MAN, Loureiro JA, Pereira MC. Receptor-mediated PLGA nanoparticles for glioblastoma multiforme treatment. Int J Pharm. 2018;545:84-92. https://doi.org/10.1016/j.ijpharm.2018.04.062.

83. Miller DS, Bauer B, Hartz AM. Modulation of P-glycoprotein at the blood-brain barrier: opportunities to improve central nervous system pharmacotherapy. Pharm Rev. 2008;60:196-209. https://doi.org/10.1124/pr.107.07109.

\section{Figures}

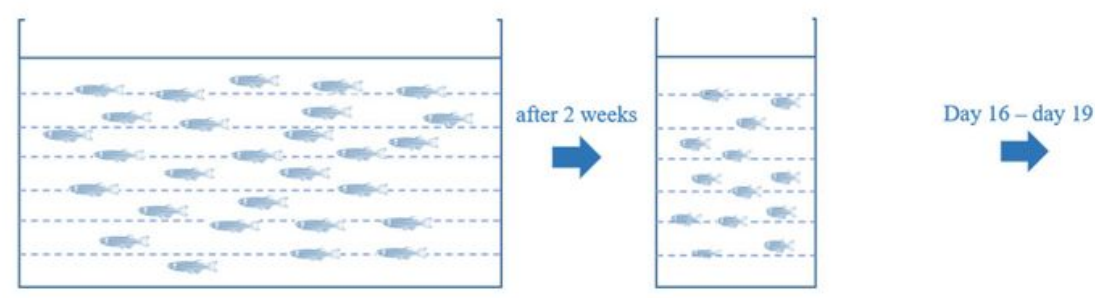

Zebrafish acclimatized in $50 \mathrm{~L}$ tank Each group of 15 zebrafish was placed in a $10 \mathrm{~L}$ tank (Administration groups: food with BTL-I ; Control \& model groups: food)

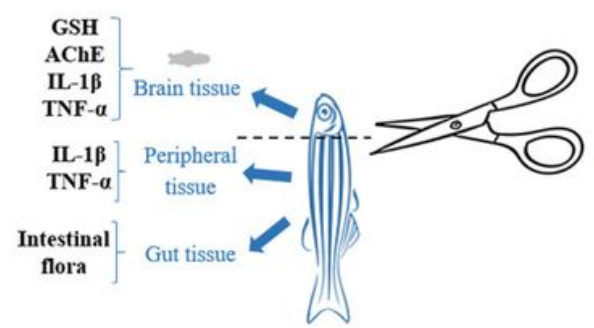

Dissected zebrafish to obtain brain, peripheral tissue and gut samples

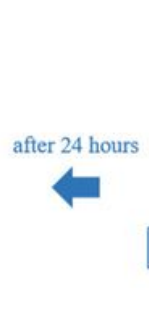
(1)

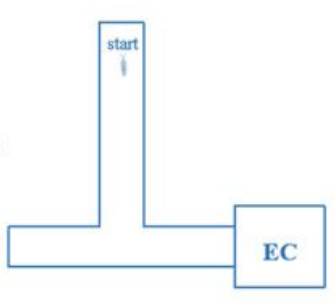

T-maze test

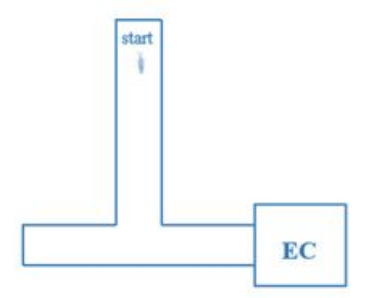

T-maze training

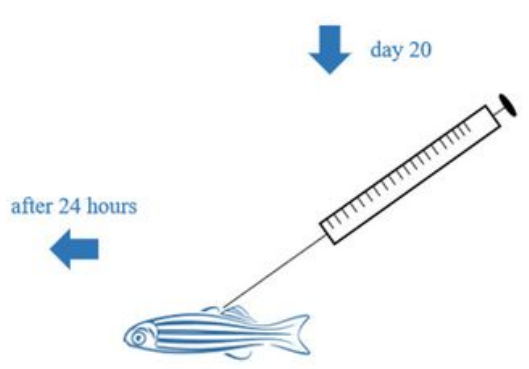

Anesthesia and i.p. injection of $\mathrm{AlCl}_{3}$ after the last day of training

\section{Figure 1}

A general diagram summarizing the experimental design used in the present study. Inset: the chemical structure of BTL-I. 

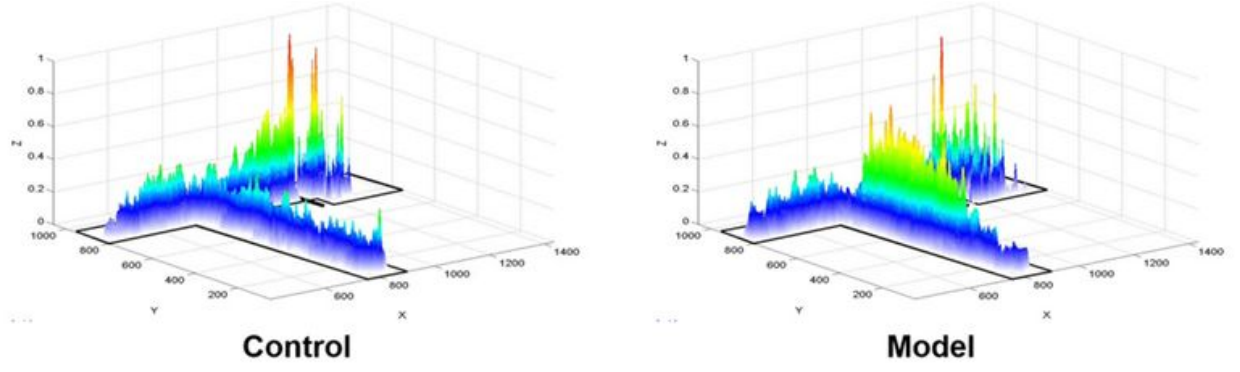

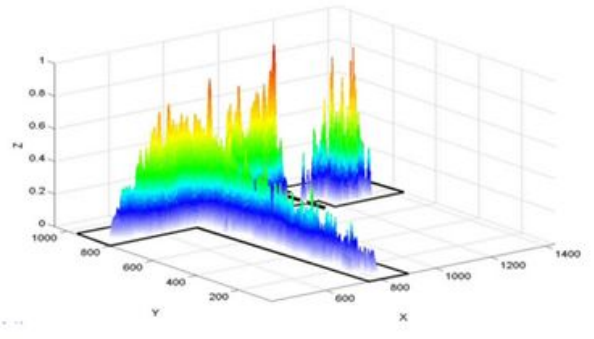

$25 \mathrm{mg} / \mathrm{kg} \mathrm{BTL}-\mathrm{I}+\mathrm{AICl}_{3}$

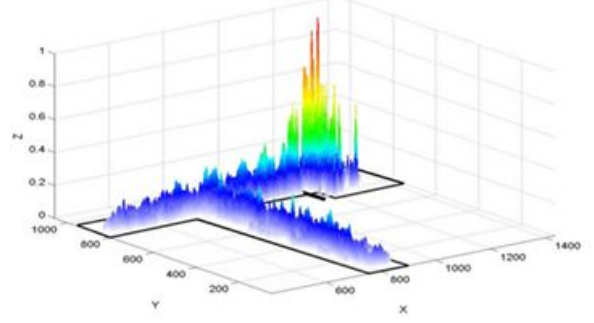

$50 \mathrm{mg} / \mathrm{kg} \mathrm{BTL-I}+\mathrm{AlCl}_{3}$

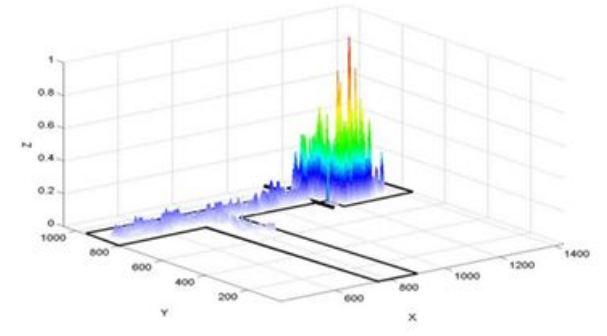

$100 \mathrm{mg} / \mathrm{kg} \mathrm{BTL}-\mathrm{I}+\mathrm{AICl}_{3}$

\section{Figure 2}

Behavioral performance of zebrafish in the enriched chamber zone of the T-maze test. a The latency (s)

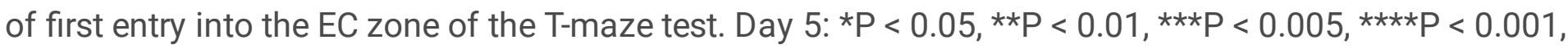
vs the control group; \#P $<0.05$, \#\#P $<0.01$, \#\#\#P<0.005, \#\#\#\#P<0.001, vs the model group. $b$ Average swimming speed on the fifth day $(n=6)$. c The number of entries to the EC zone on the fifth day $(n=6) . * P$ $<0.05,{ }^{\star} \mathrm{P}<0.01,{ }^{\star * \star} \mathrm{P}<0.005,{ }^{\star \star \star *} \mathrm{P}<0.001$, vs the control group; $\# \mathrm{P}<0.05, \# \# \mathrm{P}<0.01, \# \# \# \mathrm{P}<0.005$, $\# \# \#$ \# $<0.001$, vs the model group. 

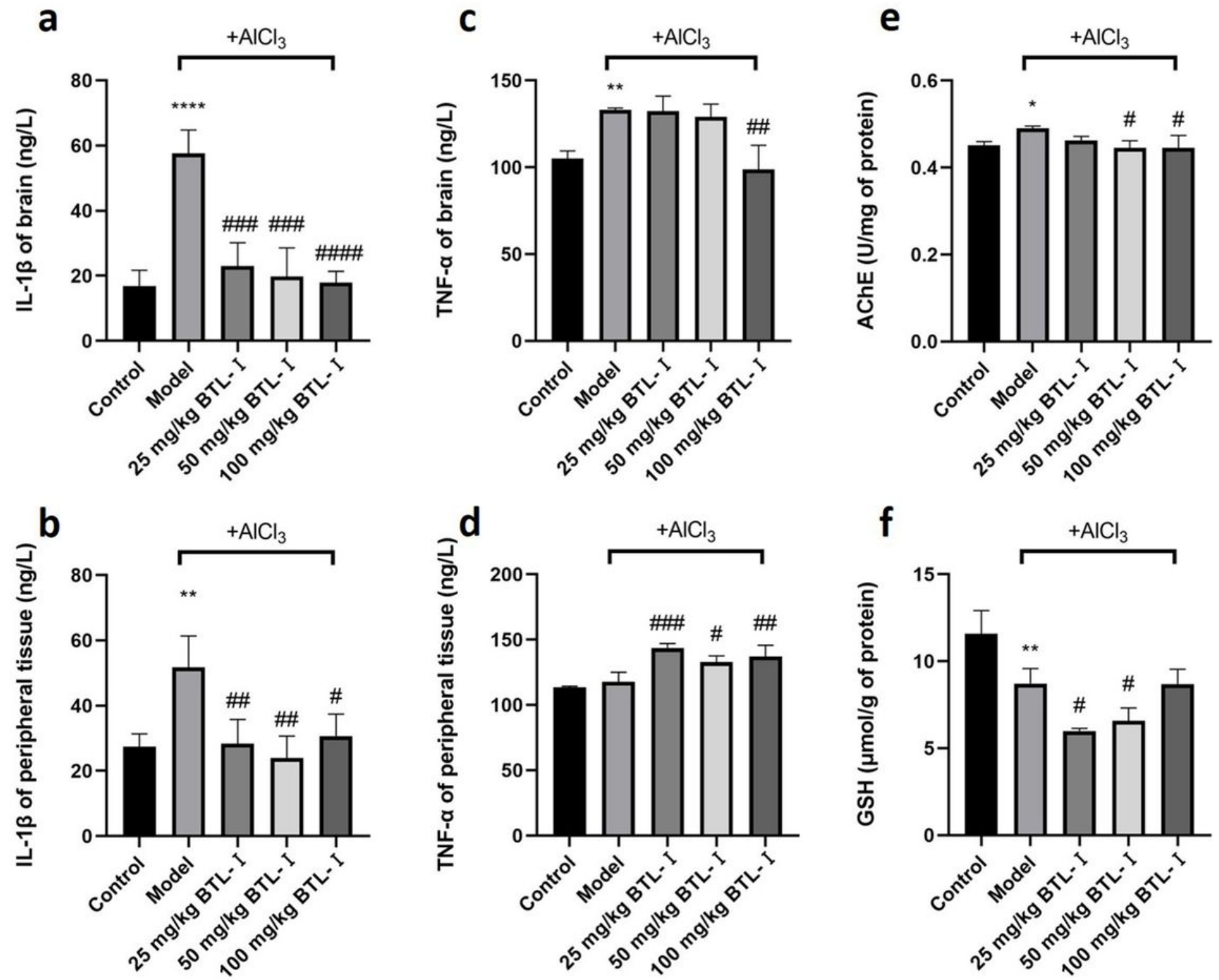

Figure 3

Heatmaps of zebrafish activity in the T-maze on on the fifth day. The X-axis and Y-axis in the figure represent the motion trajectory of zebrafish, while the Z-axis represents the residence time of zebrafish. The higher the Z-axis, the longer the residence time of zebrafish at a certain point. 
a

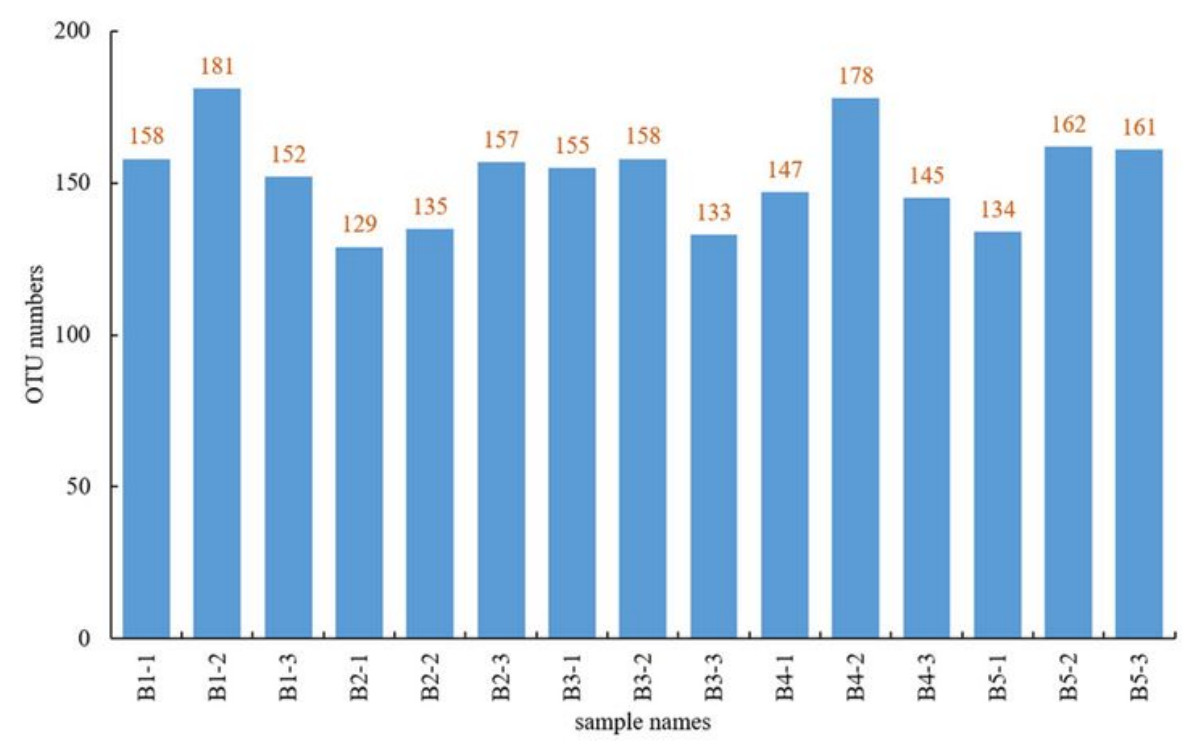

b

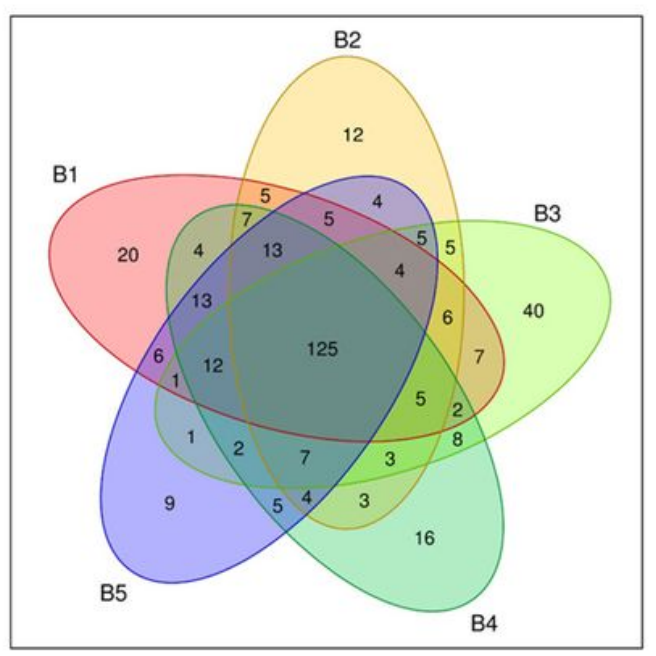

\section{Figure 4}

The results of biochemical indexes of zebrafish ( $n=3)$. a GSH content in zebrafish brain. b AChE activity in zebrafish brain. $\mathrm{c} \sim \mathrm{fIL}-1 \beta$ and TNF-a content in zebrafish brain and peripheral tissue. ${ }^{\star} \mathrm{P}<0.05$, ${ }^{\star \star} \mathrm{P}<$

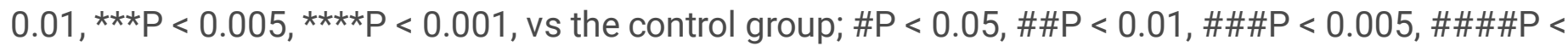
0.001 , vs the model group. 

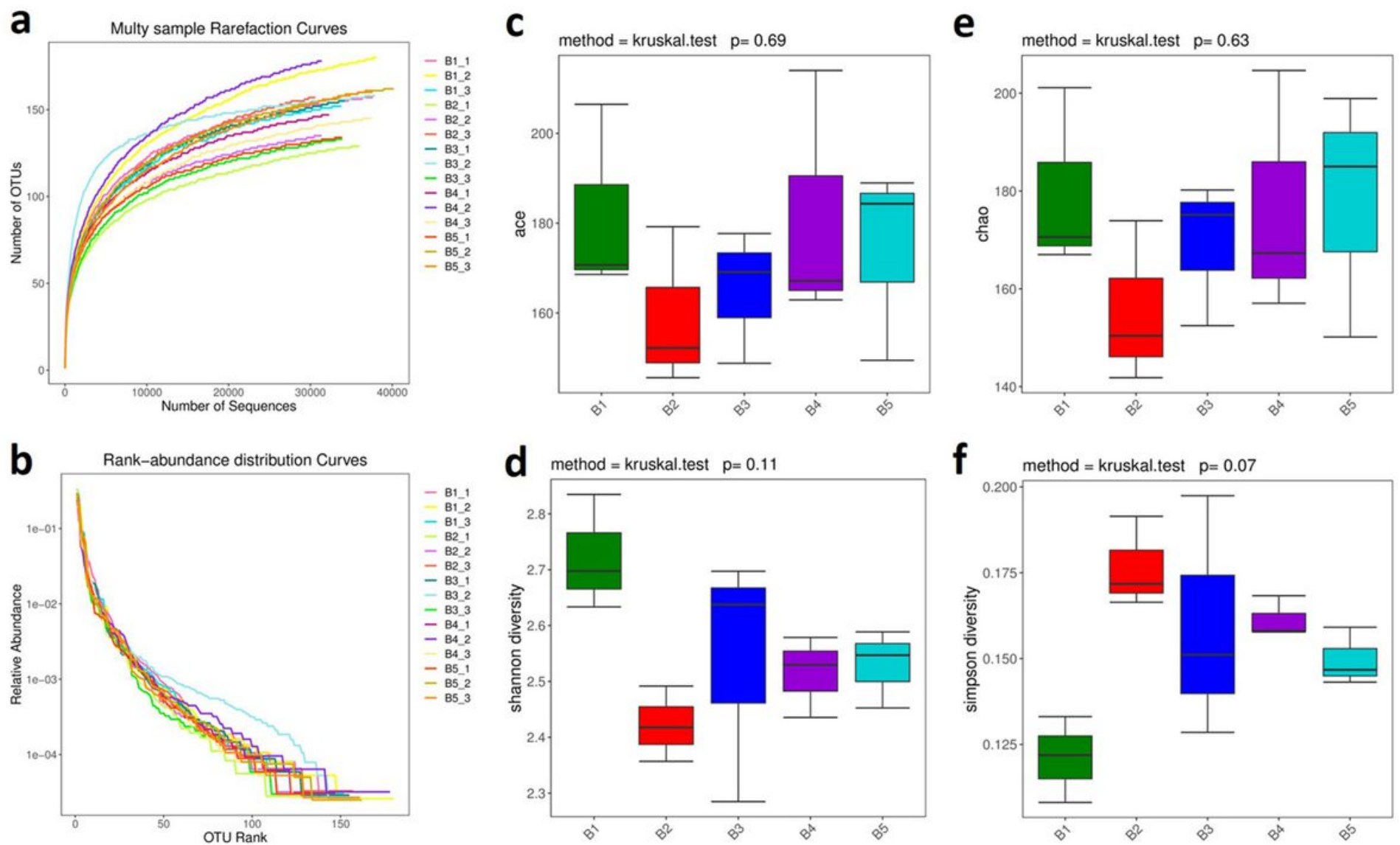

Figure 5

Statistics of the OTUs. a Statistics of the OTUs of 15 samples b Differences in the distribution of OTUs between groups using the Venn diagram. Group B1: model, Group B2: control, Group B3: 25 mg/kg BTL-I + AlCl3, Group B4: 50 mg/kg BTL-I + AICl3, Group B5: 100 mg/kg BTL-I + AlCl3, the following were the same. 

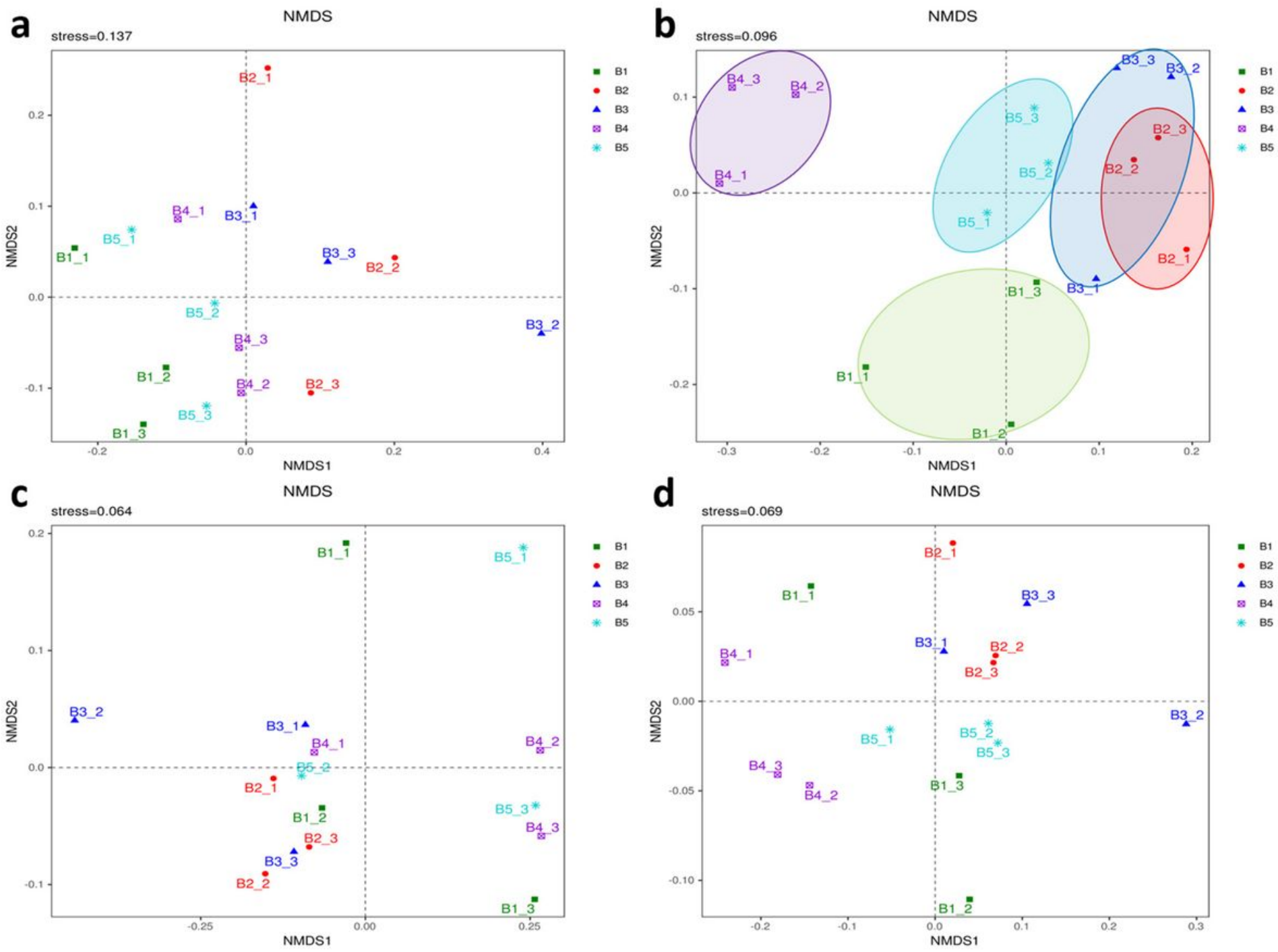

Figure 6

Alpha-diversity. a The rarefaction curves. b The rank-abundance curves. $\mathrm{c} \sim \mathrm{f}$ Alpha indices. 
a
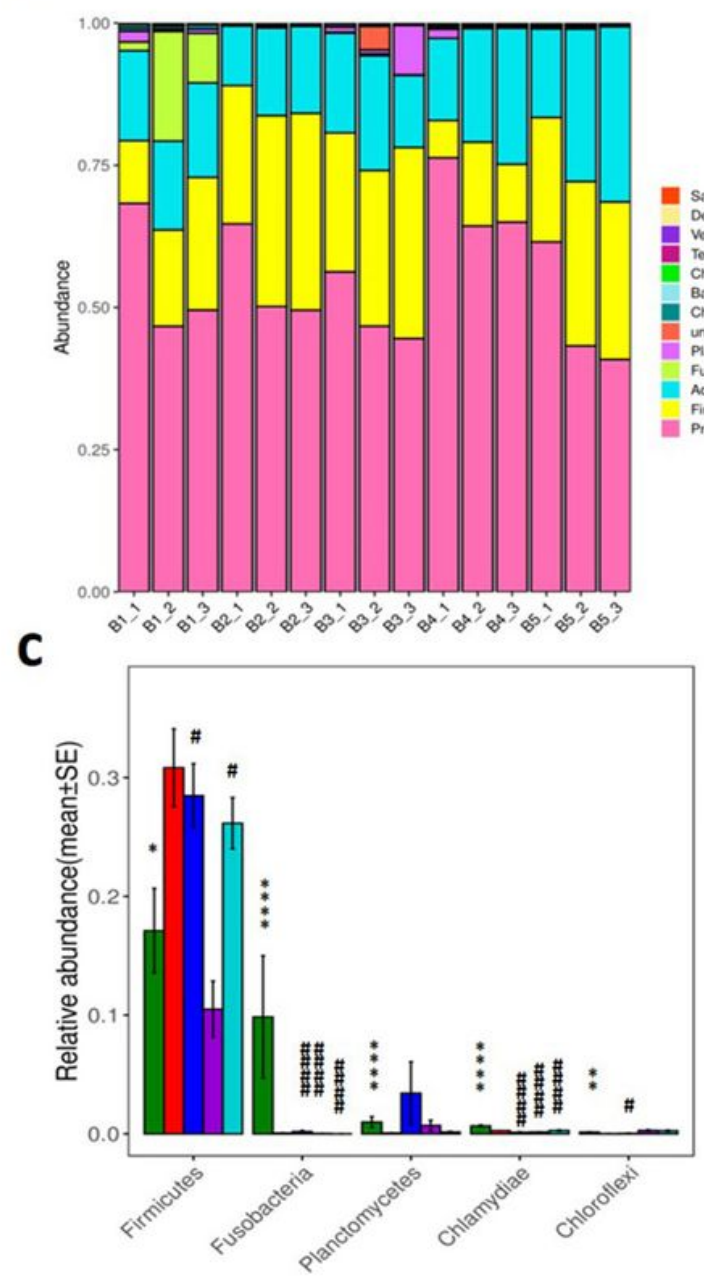

b
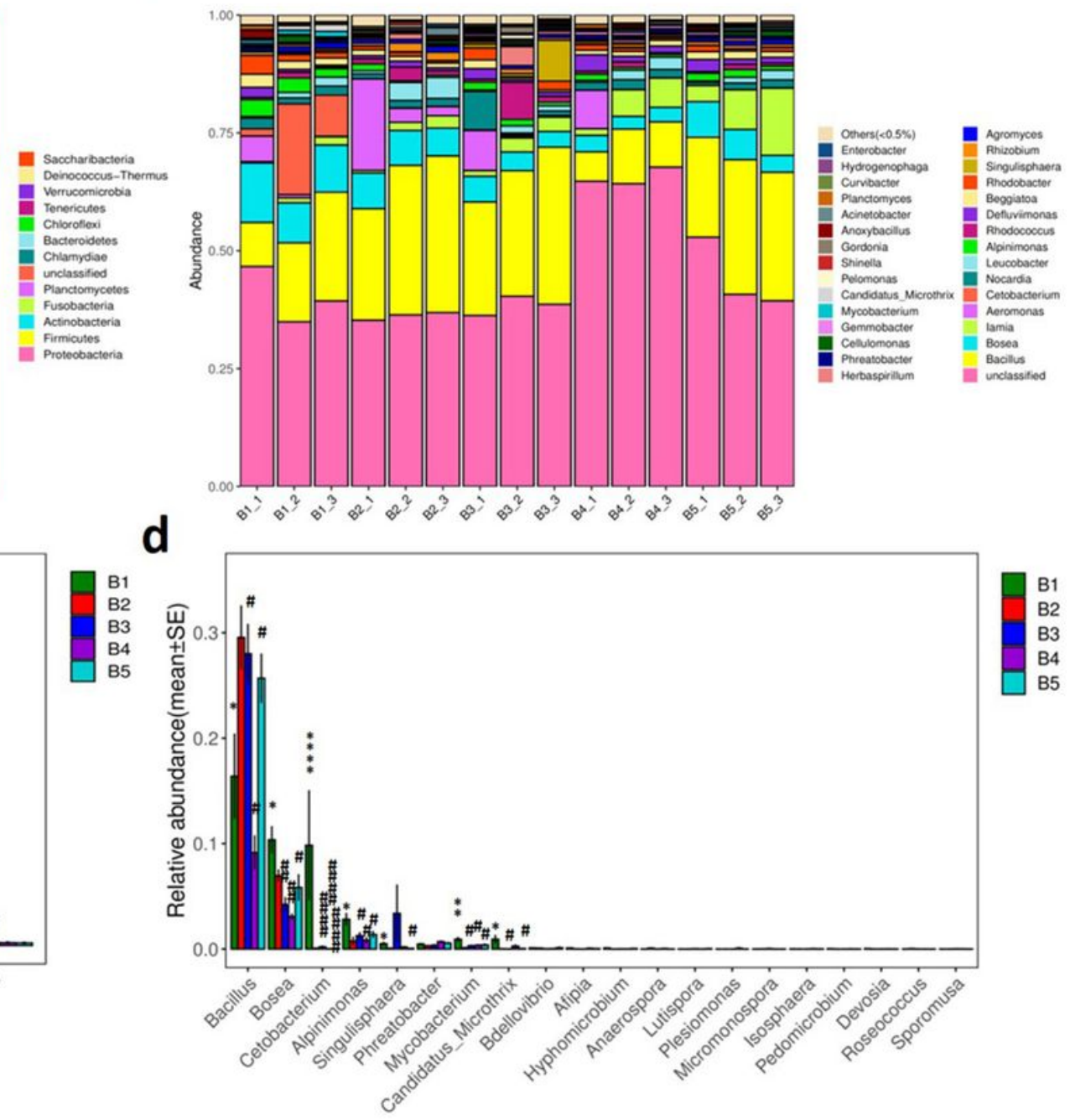

Figure 7

Beta diversity. a Jaccard algorithm (stress value $=0.137$ ). Only the presence or absence of OTU in the sample was considered, not the abundance. b Bray-curtis algorithm (stress value $=0.096$ ). Both the presence or absence of OTU in the sample and the abundance were considered. c unweighted-UniFrac algorithm (stress value $=0.064$ ). It only considers whether the sequence was present in the community, not the abundance of the sequence. $d$ weighted-UniFrac algorithm (stress value $=0.069$ ). It accounts for the abundance of sequences on the basis of unweighted-Unifrac and was able to differentiate species abundance. 
a
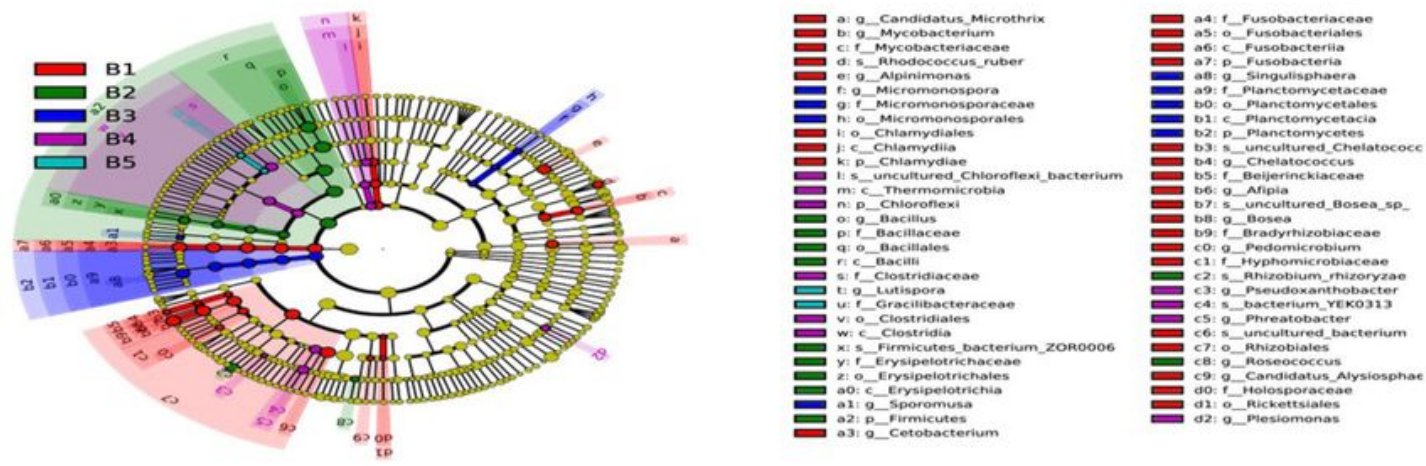

b

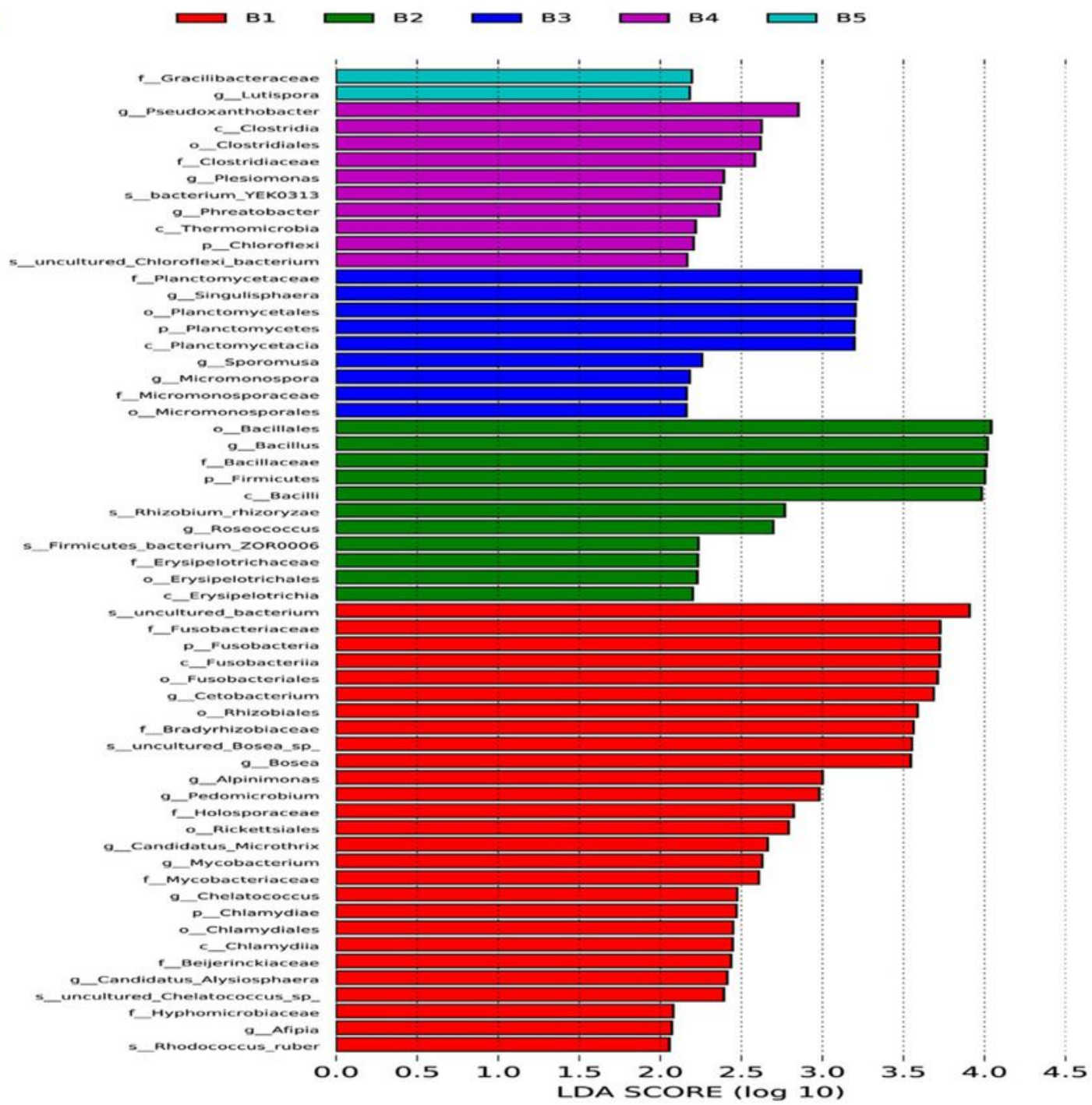

\section{Figure 8}

Relative abundance ( $a$ and $b$ ) and analysis of differential microorganisms ( $c$ and d). $a$ and $c$ Results of

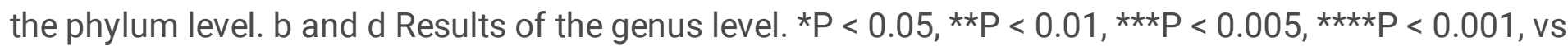
the control group; \#P $<0.05$, \#\#P $<0.01$, \#\#\# $<0.005$, \#\#\#P $<0.001$, vs the model group. 

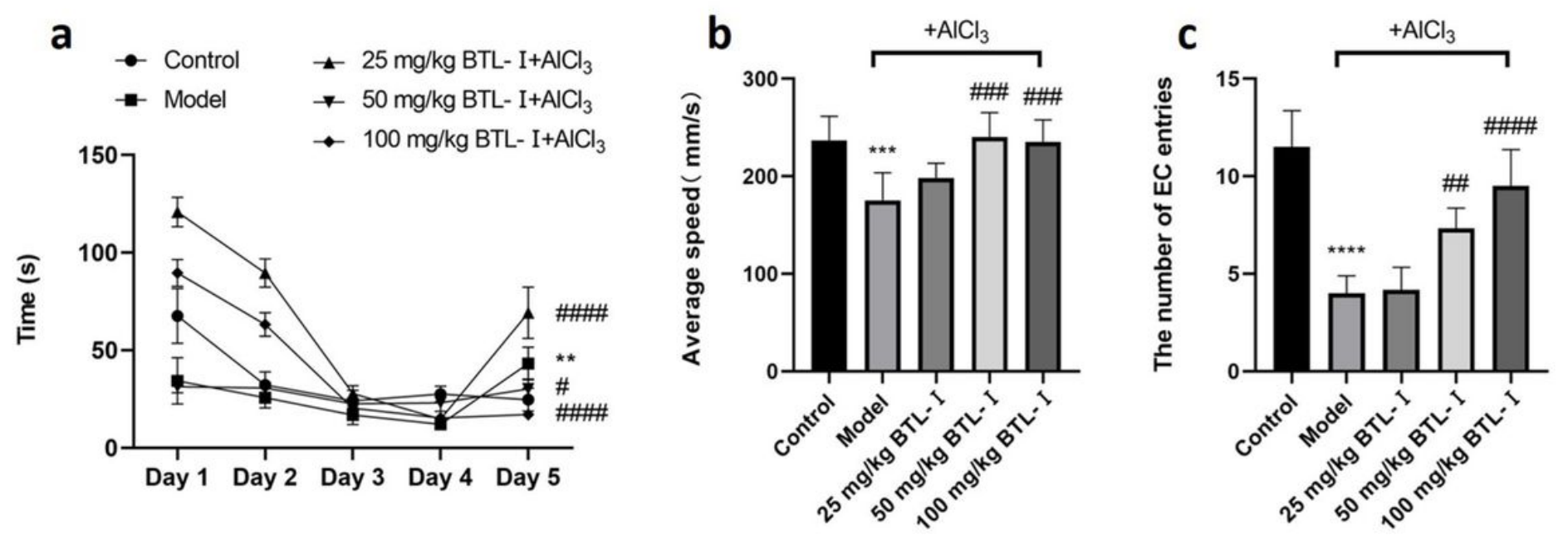

Figure 9

LDA Effect Size analysis. a Branching diagram of the evolution of different species between the control, model and experimental groups. b Bar graph of LDA values for different species.

\section{Supplementary Files}

This is a list of supplementary files associated with this preprint. Click to download.

- Supportinginformation.docx 